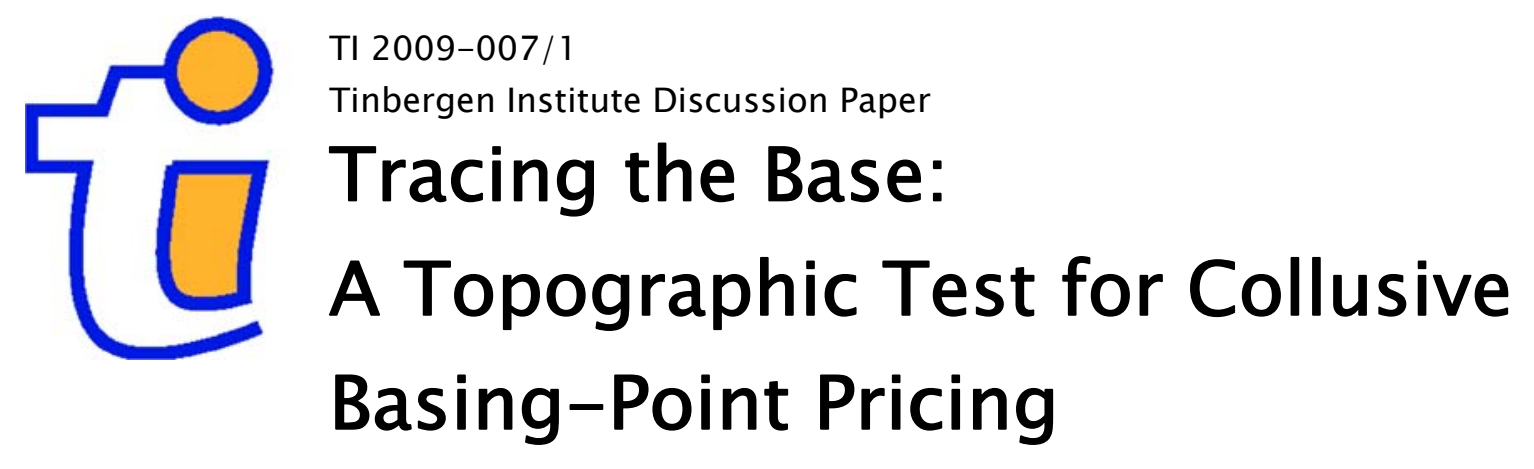

Iwan Bos'

Maarten Pieter Schinkell,2

' Dept. of Economics and ACLE, University of Amsterdam;

2 Tinbergen Institute. 


\section{Tinbergen Institute}

The Tinbergen Institute is the institute for economic research of the Erasmus Universiteit Rotterdam, Universiteit van Amsterdam, and Vrije Universiteit Amsterdam.

Tinbergen Institute Amsterdam

Roetersstraat 31

1018 WB Amsterdam

The Netherlands

Tel.: +31(0)205513500

Fax: $+31(0) 205513555$

Tinbergen Institute Rotterdam

Burg. Oudlaan 50

3062 PA Rotterdam

The Netherlands

Tel.: + $31(0) 104088900$

Fax: $+31(0) 104089031$

Most TI discussion papers can be downloaded at http://www.tinbergen.nl. 


\title{
Tracing the Base: A Topographic Test for Collusive Basing-Point Pricing*
}

\author{
Iwan Bos ${ }^{\dagger}$ and Maarten Pieter Schinkel ${ }^{\ddagger}$
}

December 2008

\begin{abstract}
Basing-point pricing is known to have been abused by geographically dispersed firms in order to eliminate competition on transportation costs. This paper develops a topographic test for collusive basing-point pricing. The method uses transaction data (prices, quantities) and customer project site locations to recover the basing-point(s) from which delivered prices were calculated. These bases are compared to the locations of the production mills in a test that discriminates between competitive and collusive basing-point pricing. We define a measure for the likelihood of collusion that can be used to screen industries that traditionally apply delivered pricing for the presence of cartels. We operationalize this screen with a software. The test is hard to beat for cartels using this otherwise elusive form of price-fixing. When a cartel was found to have abused the basing-point system, our method can be used to estimate antitrust damages.
\end{abstract}

Keywords: basing-point pricing, cartels, detection, antitrust, damages JEL-codes: L41, K42, C12

*We thank Anita van den Berg, Arnoud Boot, Joseph E. Harrington Jr., John Kwoka, Giuseppe Dari-Mattiacci, Margaret Levenstein, Jan Tuinstra and Jeroen van de Ven, as well as participants of the January 2007 NIE conference in Norwich, the 2007 IIOC meetings in Savannah and the 2007 EARIE conference in Valencia for comments to earlier versions of this paper. Excellent research assistance was provided by Eelko Ubels. Opinions and errors remain ours.

${ }^{\dagger}$ Department of Economics and ACLE, University of Amsterdam.

$\ddagger$ Department of Economics and ACLE, University of Amsterdam. Corresponding author at: Roetersstraat 11, 1018 WB Amsterdam, The Netherlands, or e-mail: m.p.schinkel@uva.nl. 


\section{Introduction}

One of the responsibilities of antitrust authorities is to discover cartels. In the past, collusive agreements have been brought to light by disgruntled employees, complaining rivals, customers seeking antitrust damages, and remorseful cartel members applying for leniency. ${ }^{1}$ It is likely, however, that cartels increasingly succeed in preventing such leaks. Conspiring managers are smart to involve employees as little as possible, for example, and to assure that their closest competitors and direct purchasers benefit rather than suffer from the existence of the cartel. ${ }^{2}$ Cartels may further find ways to dissuade their members to apply for leniency, for example by each putting up collateral that falls to the other cartel members in the event of one of them defecting from the collusive agreement. For these reasons, it is essential that public enforcement produces a sufficiently high probability of discovery across the board through active cartel detection.

Economic theory can advise in the design of detection mechanisms by identifying 'tell-tale signs' of collusion. An emerging research area of cartel detection, recently surveyed in Porter (2005) and Harrington (2008), puts emphasis on revealed characteristics of cartel behavior for this purpose. ${ }^{3}$ The approach is to distinguish collusive from competitive patterns in common observables. Significant output reductions, structural breaks and reduced variations in time-series of prices, or in prices across producers and customers can be indicative of collusion. Likewise, sudden changes in conditions of sales or quality, unusually low entry and exit frequencies, persistent excess capacity, or strongly correlated market shares and stock price values may raise suspicion.

When antitrust authorities monitor markets for suspicious behavior, clever conspirators devise ways to dodge detection. Even if only a limited number of active cartels is so discovered - after all, every test can be beaten - tests for collusion will often make internal coordination amongst prospective cartel members more difficult and dangerous. The need to try to fly under the radar is likely to depress cartel profits. In this sense, active detection can make collusion less attractive. It is essential, therefore, that the antitrust authorities stay on top of their game of hide-and-seek with professional colluders, and arm themselves with the latest detection technology.

One particularly sophisticated way in which cartels can design and cover up their

\footnotetext{
${ }^{1}$ See McAnney (1991) or Levenstein and Suslow (2006). In the past decade, cartel enforcement in both the US and the European Union has relied heavily on applications for leniency.

${ }^{2}$ For a mechanism to tacitly imply direct purchasers in an upstream cartel, see Schinkel et al. (2008).

${ }^{3}$ See also Porter and Zona (1993, 1999), Bajari and Ye (2003) and Abrantes-Metz et al. (2006).
} 
price cartel is by abusing the basing-point system. Basing-point pricing can develop under delivered pricing, which is pricing for product delivered inclusive of transportation costs. When producers are somewhat dispersed, they can each calculate their bids from locations that are not necessarily their own mill sites. As a result, buyers receive the same price quote from (at least two) sellers regardless of the sellers location, even if their transportation costs to the locations are different. Delivered pricing is typically observed in industries that produce a homogeneous bulky product that requires specialized transport to project sites, which forms a substantial part of total costs. Examples are gravel and liquid concrete in construction, oversized steel beams in shipbuilding and toxic chemicals in industry.

In competition, producers can each use the location of the rival that is nearest to the order location to calculate their freight-inclusive bid and so gain a modest economic profit, depending on the amount of geographical product differentiation. The basing-point pricing system's potential for anticompetitive abuse lies therein that a geographically isolated cluster of firms can conspire and agree to all use one or more distant base locations instead. These collusive bases could be the mill location of a distant outsider. It can also be a fictitious point far away from every cartel member. Calculating prices from such 'phantom bases', all cartel members charge transportation costs that are not actually made. In this way, the firm that gets the order can reap cartel profits in the form of phantom-freight charges. With a regular stream of more or less evenly placed orders, all cartel members gain from this agreement.

Basing-point pricing came under antitrust scrutiny in the U.S. in the first half of the 20th century. In 1924, the Federal Trade Commission (FTC) ordered the United States Steel Corporation to stop using Pittsburgh as the basing point for steel produced and sold in the Chicago area. ${ }^{4}$ In Cement Institute in 1948 the U.S. Supreme Court found that basing point pricing facilitates collusion, after which the practice was long treated as a per se antitrust violation. ${ }^{5}$ After that, the FTC brought only few basing-point pricing cases, however, and ultimately lost, after it had stepped up enforcement again in the late 1970's, in Boise Cascade (1980) and DuPont (1984). ${ }^{6}$ Boise Cascade concerned the softwood-plywood industry, in which Portland served as a single base location from which incumbent producers in the coastal areas of the Pacific Northwest together with new entrants in southern states like Louisiana

\footnotetext{
${ }^{4}$ Matter of the United States Steel Corporation, 8 F.T.C. 1 (1924). See Commons (1924).

${ }^{5}$ Cement Institute vs. FTC, 333 U.S. 683 (1948). See Kaysen (1949) and Loescher (1959).

${ }^{6}$ Boise Cascade Corp. v. FTC 637 F.2d 573 (9th Cir. 1980) and E.I. duPont de Nemours 8 Co. v. FTC 729 F.2d 128 (Second Cir., 1984).
} 
and New Orleans charged freight on deliveries nationwide. ${ }^{7}$ In DuPont, uniform delivered pricing was alleged to have been one of several devices that facilitated collusion in the sales of ethyl. ${ }^{8}$ Suspicious patterns in delivered pricing have also been found in Europe, Japan and Great Britain. ${ }^{9}$ Nevertheless, courts have increasingly held that without explicit evidence of an agreement, plaintiffs must be able to show anticompetitive intent, or a lack of legitimate business reasons for the challenged practices. ${ }^{10}$ In the past quarter century, there has been little or no enforcement of basing-point pricing and the debate about it seems to have withered.

Delivered pricing with basing points is quite a neat collusive mechanism, however. It has a number of benefits for a cartel that manages to abuse the system, including high profits and a low risk of discovery. Once the principle pricing rule is commonly understood - which is relatively straightforward, since it uses the actual transportation costs formula - basing-point pricing requires little to no communication between the cartel members. Essentially, all that is needed to fix the prices of orders of all different shapes and sizes are the geographical coordinates of the commonly used collusive base point location(s). These could be just two numbers $-x$ degrees latitude, $y$ degrees longitude communicated publicly, without raising any suspicion. There is no need for executive meetings in which to allocate heterogenous project or negotiate complex menus of prices and volumes, which leave evidence of collusion. Furthermore, it is often hard to distinguish between collusion and competition purely on the basis of observed transaction prices. The practice has the appearance of genuine competition and may thus escape common screening methods and damages assessments.

In this paper, we develop a method to test for the presence of collusive basingpoint pricing. Our test uses transaction data (volumes and prices) and information on customer locations to recover the base locations used to calculate the bid by a suspected cluster of firms. The traced bases are compared to the mill locations. If the found base locations are far away from all firms, there may have been collusion. If they coincide with various firm locations, bidding is consistent with competition. On this principle, we develop a measure for the likelihood of collusion, as well as a software that can be used to screen large amounts of data for possible collusive bases.

Our method for tracing basing points is conceptually akin to a forensic technique known as geographic profiling, which is used to find serial offenders, such as murderers

\footnotetext{
${ }^{7}$ See Carlton (1983).

${ }^{8}$ See Hay (1999).

${ }^{9}$ See Greenhut (1981) and Haddock (1982).

${ }^{10}$ See Loescher (1980) and Cabou et al. (1992).
} 
or arsonists. ${ }^{11}$ When several bodies are found at different crime scene locations, which are suspected to have all been the work of one and the same serial killer, this method uses the location coordinates to triangulate the area where the serial killer is likely to reside. The same principle can be applied to the various locations of fires in cases of arson. Geographical profiling uses the principle that the modus operandi of serial offenders typically include that such criminal acts are committed at locations that form a distance pattern around the perpetrator's base. The area may be further shaped by geographical restrictions on ease of access, such as lakes, forests, mountains and industrial areas. Such constraints are incorporated in software of detailed 3D maps and used to locate jeopardy areas for repeat offenders. The success of these computer programs in supporting law enforcement has been such that a number of them are endorsed by the U.S. Department of Justice. ${ }^{12}$

The remainder of this paper is organized as follows. The next section explains the practice of basing-point pricing in detail and summarizes the debate on its competitive nature. Section 3 develops a model of spatial competition between a given and isolated cluster of firms. We introduce conditions that suffice to fully characterize competitive and collusive basing-point pricing in this model. Section 4 illustrates how in this setting collusive basing-point pricing may escape some of the known methods of detection. Section 5 develops the principle of our topographic test. In Section 6, we operationalize the test in an algorithm. Section 7 concludes. A software developed for tracing bases is introduced in Appendix A.

\section{Basing-Point Pricing}

Under delivered pricing, shipping to customers is arranged by each seller at a price per order that includes production costs, transportation and freight insurance. Industries that apply delivered pricing often produce homogenous bulky products for manufacturers or wholesale intermediaries in geographically clustered production plants. ${ }^{13}$ The nature of these types of products typically means that they require special means of transportation, to guard quality, for example in the case of liquid concrete or asphalt, or to assure safety, such as in oversized loads or toxic chemicals. Although such specialized transportation could in principle be arranged by the buyer and offered 'free-on-board' at the mill, delivered pricing is often practical and

\footnotetext{
${ }^{11}$ See Rossmo (1999) and Canter (2003).

${ }^{12}$ These softwares include Rige ${ }^{\circledR}$, Dragnet and CrimeStat-see http://www.ojp.usdoj.gov/nij/maps/gp.html. Most of these programs originated in academic research. Several of them have also been commercially developed for use in law enforcement.

${ }^{13}$ See Soper et al. (1991) for examples of industries that applied delivered pricing.
} 
efficient for such products. Producers have specially modified trucks and equipment, for example, and can combine deliveries. ${ }^{14}$

Delivered pricing allows for basing-point pricing when firms are geographically (somewhat) dispersed. The principle mechanism of the basing-point pricing system is illustrated in Figure 1, which gives a bird's eye view of a local market with three firms and three customers. Consider this cluster as a regional market that is isolated from distant competitors. Production of a homogeneous commodity takes place at three competing mills, located at $y_{j}, j=1,2,3$. These locations are connected by the dark-lined triangle in the figure. Customer projects are situated around the mills at $x_{i}, i=1,2,3$. At each project location, there is a fixed demand for the commodity at a sufficiently high willingness to pay. The cost of production at all plant locations are identical.

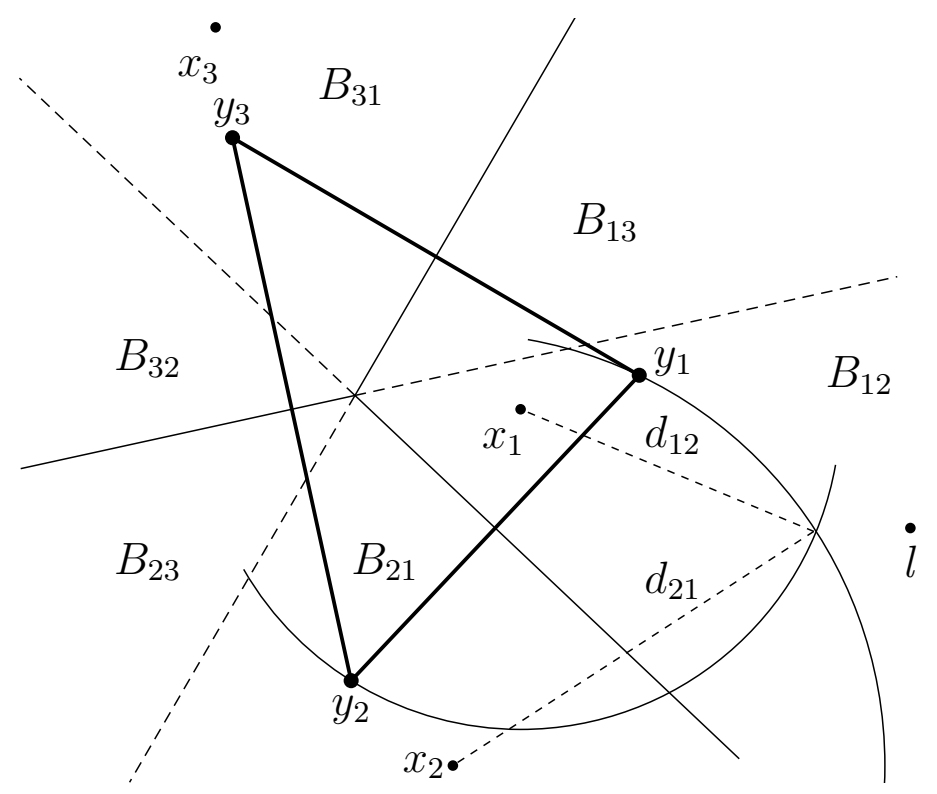

Figure 1: Bird's eye view of basing-point pricing in a regionally isolated market.

The geographical locations of plants and projects give each producer a natural home market of customers that are closest to it. As long as no two plants are exactly at the same location, producers are in imperfect competition. When mills all ship at the same transportation costs that increase in the distance of shipping,

\footnotetext{
${ }^{14} \mathrm{~A}$ part of the literature is concerned with the question under which conditions free-on-board pricing is the optimal competitive strategy, rather than delivered pricing. See Espinosa (1992).
} 
the boundaries of each producer's home market are halfway between the various production locations. The solid outgoing line-grid in Figure 1, which is constructed by placing lines orthogonal to the lines that connect the firm locations, halfway between each two plants, represents these boundaries.

When mills compete for customers, each producer can make a positive economic profit on those customers that are located within its home market as a result of geographical product differentiation. Under competitive basing-point pricing, sellers can perfectly price discriminate and charge each customer a total delivered price that is equal to the production costs for the volume plus the transportation costs that the nearest competitor would need to make to serve this customer. Since the seller itself is closer to the customer, it makes an economic profit that is equal to the difference between the price charged and the actual shipping costs, so-called 'phantom freight'. The nearest competitor cannot undercut this offer, since that would imply a loss, for it does need to make the actual transportation costs charged. ${ }^{15}$ At best, the nearest competitor could meet the bid, so that the customer receives two identical price offers from these firms, even though their distances to the project site differ.

The extended dashed-line grid in Figure 1 divides the geographical market further into customer location categories. In the following, area $B_{j v}$ is referred to as the 'base area' in the home market of firm $j$ in which it charges customers from the location of firm $v$, where $v$ indicates the nearest competitor. The geographical characteristics of the market thus define a multiple basing-point pricing pattern in competition.

If transportation costs as a function of distance differ between the firms, for example because a firm benefits from combined shipping or a more efficient means of transportation, the natural market division is more complicated and firms may deliver profitably in markets closer to other firm's production locations. This practice is known as 'cross-hauling'. ${ }^{16}$

Producers can also decide to conspire to exploit market circumstances and all use a remote base point location in calculating their offers. This eliminates competition on transportation costs between them. The collusive bases would be one or more arbitrarily agreed locations, or natural focal points, such as a common port location, as long as it is sufficiently far away from customers. Alternatively, the location of a distant rival that is not part of the cartel but within reach of its customers is a natural candidate base location. This choice assures that the rival cannot undercut the local cartel and enter into the market of any of its members.

By charging the going mill rate plus freight from the collusive base(s), cartel members can reap anticompetitive phantom freight. Such an abuse of the basing-

\footnotetext{
${ }^{15}$ If this does happen, it is referred to as 'freight absorption'.

${ }^{16}$ See Haddock (1982).
} 
point system can sustain a cartel if customers and mills are located relatively closely together, and producers can agree on a collusive base point that is sufficiently far removed from their cluster. In such circumstances, applying the collusive base returns higher (expected) phantom freight for all cartel members. Whether a market can profitably be cartelized in this way depends on the distribution of demand, relative to the locations of the mill sites. It is difficult to formulate an acceptable set of general conditions under which it always is. In constructed cases - for example with a cluster of demand very far away from a cluster of mill locations, around a mine in a thinly populated area, at comparable distance to which there is a rival mill as well - a local basing-point cartel may not work. At the same time, however, it is straightforward to construct generic examples in which collusive basing-point pricing is a very lucrative proposition.

In Figure 1, point $l$ is such a collusive phantom base location when transportation costs increase linearly in distance, so that there is a positive cartel profit for each member as long as the distance from $l$ to any of the customers $x_{i}$ is larger than the distance from $x_{i}$ to any cartel member's nearest competitor $y_{v}$. That is, outside the circle with radius $d_{12}$ between customer 1 and firm 2, from which firm 1 charges customer 1 transportation costs in competition, firm 1 earns a net cartel profit. Analogously, firm 2 makes a cartel profit on its customer 2 , since $l$ is outside the radius $d_{21}$ from $x_{2}$ to $y_{1}$. Finally, location $l$ is obviously profitable for firm 3 to use on its customer 3 (boundary not drawn). In general, there are many profitable single collusive base point candidates, as well as more complex collusive systems that use multiple basing points, also when transportation costs are not linear in distance.

As emphasized in the introductory section, collusive basing-point pricing has a number of benefits for a cartel in this type of markets. The principle is relatively easy to implement, and once established, there is no need for extensive communication between the cartel members. This helps to sustain the cartel while creating minimal proof of a conspiracy. Orders of all shapes and sizes are all individually overcharged on the basis of agreement on just two geographical coordinates. Moreover, the bids that a customer receives from different firms are identical, without the cartel needing to coordinate each case separately. The system furthermore returns a wide bid spread across customers, as project sites are each located differently relative to the collusive base. This price pattern can be similar to one that would emerge under competition, when firms that are far removed from a project site would refrain from bidding, so that customers only receive the identical bids of the (minimally two) closest rivals. This makes that the cartel can pass for a competitive industry without raising suspicion with customers or the antitrust authorities, even when bidding information is publicly available. In transaction price data only, collusive basing- 
point pricing need not leave any obvious traces.

At the same time, the system allows cartel members to straightforwardly monitor their coconspirators for cheating. ${ }^{17}$ Each cartel member is able to simply calculate what should have been the collusive offers of its coconspirators, to see if the others may be undercutting the agreement. Furthermore, collusive basing-point pricing includes a natural credible punishment strategy to discipline discovered cheaters. If a cartel member is found out defecting from the collusive basing-point strategy, its production plant can be made a 'punitive base', that is, the base location used by the other cartel members in their subsequent price offers. ${ }^{18}$ This punishment is straightforward to implement. While costly for the defector, the punishment is relatively inexpensive for the loyal cartel members - somewhat depending on their distances to the defector relative to their customer bases. Finally, collusive basing-point pricing is a particularly suitable strategy for a cluster of closely located producers that seeks to jointly prevent entry from distant rivals into their local cluster's home market. By using the mill locations of those rivals as collusive base locations, the local cartel deters entry by limit pricing, while all cartel members can make a positive cartel profit. $^{19}$

The competitive nature of delivered pricing has been much debated. Machlup (1949) and Stigler (1949) were among the first to argue that basing-point pricing can facilitate collusion. Thisse and Vives (1988, 1992), Benson, et al. (1990) and Levy and Reitzes (1993) have shown that it is unlikely that the basing-point system develops noncooperatively in competition without explicit communication. Others, including Clark $(1943 ;$ 1949), Carlton (1983) and Haddock $(1982,1990)$, have defended basing-point pricing as an efficient form of spatial competition and an unlikely system to be adopted by a monopolist or a cartel.

A number of weaknesses of basing-point pricing as a mechanism of collusion have been pointed out in this literature. There need not always be a natural candidate collusive base location, and since individual cartel profits increase in the distance of the collusive base location to its own customers, each cartel member would prefer the collusive base to be far away from its home market. In its most basic form, the cartel arrangement does not include an explicit division of the market if all cartel members offer the same high price to each customer. ${ }^{20}$ When buyers choose more or

\footnotetext{
${ }^{17}$ See Benson et al. (1990).

${ }^{18}$ Loescher (1959) reports on this punishment strategy having been used in the cement industry.

${ }^{19}$ In Addyson Pipe and Steel, a group of southern and Mid-western iron pipe manufacturers (the Addyston Group) collectively tried to block entry into its home market by establishing a collusive basing-point at the nearest cluster of competitors in the east. See U.S. v. Addyston Pipe and Steel, 175 U.S. 211, 1899. See Levy and Reitzes (1993) for a theoretical analysis.

${ }^{20}$ See Carlton (1983).
} 
less randomly with which producer to order, each cartel member risks receiving little or no orders for considerable periods of time, even if orders may work out more or less evenly over all firms in the long run. As a result, the cartel may need to apply an end-of-year compensation scheme - and a risky bookkeeping that comes with it. This would add to the complexity of the arrangement and to the risk of discovery.

Uncertainty in the distribution of orders, combined with quoted prices often being private information, could also make the detection of chiseling more, rather than less difficult compared to more explicit cartel agreements. Also, firms would regularly need to deliver in other firms' home markets, thus transporting inefficiently and suffering from freight absorption. ${ }^{21}$ In addition, delivery outside the home market would rarely be observed among competing firms, unless transportation costs differ strongly between different producers, so that if it is observed, it would create suspicion of an illegal arrangement in and of itself. Taken together, these drawbacks would make basing-point pricing an unlikely choice for coordinating price fixing. Instead, where delivered pricing and cross-hauling are applied, these pricing strategies would typically be efficient. ${ }^{22}$

Most of these suggested problems with collusive basing-point pricing can, however, be quite easily overcome by small modifications of the basic form of abuse outlined above. By using multiple collusive bases and/or rotating them at regular intervals, for example, the cartel can distribute its profits evenly over time. The cartel could further agree on simple distance related market sharing rules, such as a fixed surcharge to tender request from outside the natural home market. This would imply an efficient division of the market along the lines of home markets, while only slightly increasing communication. Observe also that customers are indifferent which cartel member to order from at equal delivered price quotes, so that they are quite likely to obey natural market boundaries and select the firm closest to them. If lasting trade relationship do not assure this, slight discounts will, so that the cartel can easily prevent suspicious and inefficient cross-hauling. ${ }^{23}$ These additions to the basic agreement do increase the complexity and risk of discovery of the cartel somewhat.

Empirical studies have remained inconclusive about the question whether basingpoint pricing is competitive or collusive. Machlup (1949) and Loescher (1959) describe collusive patterns in the cement industry. Karlson (1990) revisits the industry data over the period 1910-1940 to find little support for competitive explanations for the practice and suggestion of collusion in the 1930's. Gilligan (1992) concludes that single basing-point pricing is unlikely to have facilitated collusion in the softwood-

\footnotetext{
${ }^{21}$ See Smithies $(1941 ; 1942)$.

${ }^{22}$ See Haddock (1982).

${ }^{23}$ See Loescher (1959).
} 
plywood industry. The study finds that while the FTC's interference reduced the phantom freight rents for the southern producers, it left the markups of the northern plywood producers unaltered, which is interpreted as suggestive of imperfect competition among the non-base-site producers, and not of collusion amongst the base-site producers.

\section{A Model of Basing-Point Pricing}

Consider a world represented by an unbounded Cartesian plane and a single homogenous product. Customer projects are distributed over the plane. At location $x_{i}$, customer $i$ has a perfectly inelastic demand for the product of order size $q_{i}$, for which it has a sufficiently high willingness to pay. Let $f(x)$ be the probability density function of a normalized single unit order from project location $x$. Total expected demand from a bounded region $\Omega \subset \mathbb{R}^{2}$ is then given by

$$
\int_{\Omega} f(x) d x
$$

We assume that demand is distributed over the world so that there are some projects everywhere, as follows.

Assumption 1 The project demand probability density function $f(x)$ is continuously differentiable and satisfies,

(i) $\int_{\Omega} f(x) d x=1$;

(ii) $f(x)>0$ for all $x \in \Omega$.

Each customer orders with the firm offering the lowest price.

There is a fixed and finite number of production mills $J$ that all produce at identical and constant marginal cost per unit of volume $c$, a fixed cost per order $F$, and without capacity constraints. Mills are located at geographically dispersed locations $y_{j}, j=1, \ldots, J$. We assume that plant locations are given and there is no entry. As a result, there is a given amount of spatial product differentiation. It is possible that two or more firms are very close together, and profits are zero in competition when they are exactly in the same location. Production plants can in principle be located anywhere in this world, yet the nature of products involved - raw materials in bulk with lower input transportation costs than output transportation costs - can dictate certain regional constraints - such as mining area's and locations that have easy access to water ways. Whenever possible, however, plants are likely to 
be located where demand is high, due to a substantial transportation cost component. In the following, we consider the cluster of $J$ producers in isolation and further abstract from any outside distant rivals.

Let the physical distance between two locations, $\alpha$ at $\left(a_{\alpha}, b_{\alpha}\right)$ and $\beta$ at $\left(a_{\beta}, b_{\beta}\right)$, be indicated by $d_{\alpha \beta}$ and defined by the Euclidian distance

$$
d_{\alpha \beta}=\sqrt{\left(a_{\alpha}-a_{\beta}\right)^{2}+\left(b_{\alpha}-b_{\beta}\right)^{2}} .
$$

Hence, $d_{y_{j} x_{i}}$ is the actual distance between firm $j$ at $y_{j}$ and customer $i$ at $x_{i}$.

Using distances, let the natural home market of firm $j$ be defined as the set of customers $H_{j}$ for which firm $j$ is closest in terms of physical distance. That is,

$$
H_{j}=\left\{\text { all customers } i \text { for which } d_{y_{j} x_{i}}=\min _{k}\left(d_{y_{k} x_{i}}\right) \text { for } k=1, \ldots, J\right\} .
$$

We assume that each customer exclusively belongs to one home market.

Each natural home market can be divided into one or more so-called 'base areas'. A base area in the home market of firm $j$ is denoted $B_{j v}$ and defined as,

$$
B_{j v}=\left\{\text { all customers } i \in H_{j} \text { for which } d_{y_{v} x_{i}}=\min _{k \neq j}\left(d_{y_{k} x_{i}}\right) \text { for } k=1, \ldots, J\right\}
$$

in which the distance $d_{y_{v} x_{i}}$ is between customer $i$ and the producer $v$ at $y_{v}$ that is located closest to that consumer, except for producer $j$. Each firm $j$ has one or more base area's, depending on the number of direct competitors, i.e., competitors whose home markets border at $H_{j}$. The collection of base areas with the same second subscript $v$ is referred to as a 'base group' $G_{v}$. Let $B_{j}$ be the set of base areas of firm $j$ - that is, collections of all base areas with the same first subscript. We denote the total number of elements in $B_{j}$ by $V_{j}$.

Given the geographical spread of all players, to deliver an order to one of its customers, firm $j$ incurs transportation costs. Let the transportation costs of firm $j$ for transporting volume $q_{i}$ from its plant at $y_{j}$ to a customer project located at $x_{i}$ be of the general form $T_{j}\left(q_{i}, d_{y_{j} x_{i}}\right)$, which are positive, continuous and differentiable functions. We assume that firms have identical transport cost structures, and that total cost of transport are increasing in distance and the volume of the order.

Assumption $2 T_{j}\left(q_{i}, d_{y_{j} x_{i}}\right)$ satisfies for all $j=1, \ldots, J$,

(i) $T_{j}\left(q_{i}, d_{y_{j} x_{i}}\right)=T\left(q_{i}, d_{y_{j} x_{i}}\right)$;

(ii) $\frac{\partial T\left(q_{i}, d_{y_{j} x_{i}}\right)}{\partial d_{y_{j} x_{i}}}>0$ and $\frac{\partial T\left(q_{i}, d_{y_{j} x_{i}}\right)}{\partial q_{i}} \geq 0$. 
Note that by assuming that production and transportation costs are identical across production plants, we rule out efficient cross-hauling. This implies that when cross-hauling is observed, it would in itself be indicative of collusion. We therefore also exclude the possibility of cross-hauling under collusion by assuming a natural market division.

Assumption 3 If a customer is indifferent between price offers from different producers, shipping will be from the mill that is closest to the project.

In competition, this assumption is innocuous. In case of cartel pricing, it implies an efficient market division mechanism, which further enhances internal monitoring by the cartel, as observed cross-hauling exposes a deviating member. Under these assumptions, it is not possible to detect collusive basing-point pricing by simply checking for cross-hauling.

In delivered-pricing systems, prices and profits are determined by distances. The system thus allows firms to price-discriminate between individual customers. Consider $d_{l x_{i}}$, the distance between customer $i$ and a given geographical location $l$-be it a firm or a distant location. Customer $i$ receives an all-inclusive price offer $P_{j i}$ from firm $j$ that is constituted as follows,

$$
P_{j i}=c q_{i}+F+T\left(q_{i}, d_{l x_{i}}\right) \text {, }
$$

in which $F$ may include any fixed component in transportation costs.

The profit firm $j$ makes on an order delivered to customer $i$ is,

$$
\pi_{j i}=P_{j i}-c q_{i}-F-T\left(q_{i}, d_{y_{j} x_{i}}\right) .
$$

Substituting (3) in (4) yields,

$$
\pi_{j i}=T\left(q_{i}, d_{l x_{i}}\right)-T\left(q_{i}, d_{y_{j} x_{i}}\right),
$$

which is the difference between actual transportation cost and the transportation cost charged to the consumer.

Obviously, $\pi_{j i}=0$ if $d_{l x_{i}}=d_{y_{j} x_{i}}$, which would be the case if producer $j$ calculates freight cost from its own mill location. Profits are positive for orders for which the actual freight costs, $T\left(q_{i}, d_{y_{j} x_{i}}\right)$, are smaller than the freight costs calculated to the customer, $T\left(q_{i}, d_{l x_{i}}\right)$ by the amount of phantom freight over $d_{l x_{i}}-d_{y_{j} x_{i}}$. Profits per project increase in phantom freight, since the actual transportation costs over $d_{y_{j} x_{i}}$ are fixed by locations $x_{i}$ and $y_{j}$, so that $\frac{d \pi_{j i}}{d d_{l x_{i}}}=\frac{\partial T\left(q_{i}, d_{l x_{i}}\right)}{\partial d_{l x_{i}}}>0$ for all $j=1, \ldots, J$ by Assumption 2. Furthermore, the difference between real and calculated freight 
charges for a given volume may increase in the volume of the order $q_{i}$, depending on the functional form of $T(\cdot) .^{24}$

\subsection{Competitive Basing-Point Pricing}

In competition, firms play a one-shot game in which plants $j=1, \ldots, J$ at $y_{j}$ simultaneously chose an action $P_{j i}$, depending on a chosen location $l$, in response to realized demand in the form of a tender request for $q_{i}$ from project site $x_{i}$, leading to a pay-off $\pi_{j i}=T\left(q_{i}, d_{l x_{i}}\right)-T\left(q_{i}, d_{y_{j} x_{i}}\right)$. The following result establishes that in competition delivered pricing allows each mill to charge competitive phantom freight from the location of their nearest competitor to each project in its home market.

Proposition 1 In competition, firm $j$ uses mill location $y_{v}$ as a base for all customers $i \in B_{j v}$ and $y_{j}$ for all $i \notin H_{j}$.

Proof. Consider a customer $i \in B_{j v}$ and, without loss of generality, suppose that the mills $j$ and $v$ use a basing point located at $l$ such that $d_{l x_{i}}>d_{y_{j} x_{i}}, d_{l x_{i}}>d_{y_{v} x_{i}}$ and $d_{l x_{i}}<d_{y_{k} x_{i}}, \forall k \neq j, v$. Hence, $T\left(q_{i}, d_{l x_{i}}\right)-T\left(q_{i}, d_{y_{k} x_{i}}\right)<0, \forall k \neq j, v$, so that we solely concentrate on mills $j$ and $v$. Calculating the bid from $l$ yields, according to (3), $P_{j i}=P_{v i}$, which by Assumption 3, gives mill $j$ the trade, so that $\pi_{j i}>0$ and $\pi_{v i}=0$. This, however, cannot be optimal for $v$, because lowering $P_{v i}$ slightly to $P_{v i}^{*}=P_{j i}-\varepsilon$, with $\varepsilon$ small but positive, shifts the trade to mill $v$ to generate $\pi_{v i}>0$ by equation (5). The best response for mill $j$ then is to always match the bid of $v$, as long as $P_{j i}^{*}=P_{v i}^{*}>c q_{i}+F+T\left(q_{i}, d_{y_{j} x_{i}}\right)$. Hence, mill $v$ 's (weakly) optimal bid equals $P_{v i}^{* *}=c q_{i}+F+T\left(q_{i}, d_{y_{v} x_{i}}\right)$, because any further lowering of the bid implies a loss. Mill $j$ therefore optimally submits $P_{j i}^{* *}=P_{v i}^{* *}$, yielding concomitant profits $\pi_{v i}=0$ and $\pi_{j i}=T\left(q_{i}, d_{y_{v} x_{i}}\right)-T\left(q_{i}, d_{y_{j} x_{i}}\right)>0$. Note that, with respect to consumer $i$, all other mills $k$ are in the same position as mill $v$. Therefore, all mills, but the mill that is located closest to the customer project, will use their own plant location as basing point.

Serving its natural home market yields firm $j$ a total profit equal to the sum of the profits it expects to earn on the customer projects in each of its $V_{j}$ base area's $B_{j v}$. These expectations are based on $f(x)$, the distribution of single order unit demand, and therefore only depend on distances. Our assumptions on the distribution of

\footnotetext{
${ }^{24}$ Note that in the basing-point price structure, the frequency of orders over time is important for profits, and the frequency of trips is likely to be inversely related to the volume of sales per order if customers, for example, save up demand to combine several orders into one. By assuming the order-frequency and the volume to be independent of price, we ignore these substitution effects.
} 
customer projects assures that $H_{j}$ is non-empty for all $j$. Hence, all mills are used as a base by at least one rival firm in competition. The expected profits earned by firm $j$ under a competitive basing-point regime can therefore be written as

$$
\pi_{j}^{c}=\sum_{v=1}^{V_{j}} \int_{B_{j v}} f(x)\left(T\left(d_{y_{v} x_{i}}\right)-T\left(d_{y_{j} x_{i}}\right)\right) d x,
$$

where $T\left(d_{y_{v} x_{i}}\right)$ is the distance between project location $x_{i}$ and the nearest rival that defines base area $B_{j v}$. The superscript $c$ refers to 'competition'.

Clearly, firms ability to earn positive economic profits depends on their relative positions in the geographical market. When mills are few and far between, competitive profits can be substantial. When they are clustered relatively close together, there is little room to price above true transportation costs. If two mills are almost exactly in the same location - say, next door to each other-they will effectively calculate transportation costs from their own product site and make almost zero profits.

\subsection{Collusive Basing-Point Pricing}

The vulnerability of the basing-point pricing system to collusion stems from the fact that the cartel members only need to agree on one jointly used collusive base location at any given point in time. ${ }^{25}$ They do this ex ante, based on the expected profits they can each generate over their home market population. That is, the expected cartel profit of firm $j$ is equal to

$$
\pi_{j}^{a}=\int_{H_{j}} f(x)\left(T\left(d_{l x_{i}}\right)-T\left(d_{y_{j} x_{i}}\right)\right) d x
$$

where $l$ is a common collusive base location. The superscript $a$ stands for 'anticompetitive'.

Agreeing on the location of the collusive base among all members of the coalition is not straightforward. Certainly, the cartel has a collective interest in choosing a base location that is sufficiently far away from the main customer projects and the

\footnotetext{
${ }^{25} \mathrm{~A}$ cartel abusing the basing-point pricing system may also use a number of different collusive base locations, for example to support a certain profit sharing rule or to avoid detection. In the following, we will analyse the use of a single collusive base at any point in time. We briefly discuss how our results transfer to collusive multiple basing-point pricing in Section 7.
} 
mill locations of its members, so that $\pi_{j}^{a} \geq \pi_{j}^{c}$ for all $j .{ }^{26}$ Yet, a distant collusive base location will always be closer to some customer projects than the serving mill is, so that expected losses are to be accepted on part of the remote projects. Typically, therefore, collusive base candidates are in the tail of the customer project distribution. Another problem for the cartel is that different distant collusive bases are most profitable for different cartel members. More specifically, each member would prefer the collusive base to be located in the farthest corner of a distant coconspirator's home market.

As explained above, when there are distant rivals that could poach the cartel's market, the location of one or more of them - in particular the closest - are natural collusive base candidates. When there is not such a natural focal point, the class of possible collusive base locations is large. We can restrict this class by the requirement that each cartel member individually increases its expected profits under the cartel regime. Making use of the fact that, since actual shipping distances and volumes remain the same, total costs in competition and collusion are the same, that is, each individual cartel member $j, j=1, \ldots J$, blocks all candidate collusive bases $l$, for which

$$
\int_{H_{j}} f(x) T\left(d_{l x_{i}}\right) d x \leq \sum_{v=1}^{V_{j}} \int_{B_{j v}} f(x) T\left(d_{y_{v} x_{i}}\right) d x
$$

where $d_{y_{v} x_{i}}=\min _{k \neq j}\left(d_{y_{k} x_{i}}\right), k=1, \ldots, J$, for all $v=1, \ldots, V_{j}$. Although quite natural, note that this blocking condition is an assumption in the sense that it rules out Pareto improving side-payments between the cartel members. In this way, it creates a larger area of blocked candidate collusive bases than strictly required to increase expected profits. ${ }^{27}$

The set of geographic locations for which condition (8) holds for firm $j$, we call $j$ 's 'blocking zone' $\mathcal{B}_{j}$. We have the following result.

Proposition 2 For each cartel member $j, j=1, \ldots J, y_{j} \in \mathcal{B}_{j}$.

\footnotetext{
${ }^{26}$ In this paper, issues of cartel stability are further ignored. It is assumed that a cartel exists whenever all members benefit from collusion over competition. Given the existence of a cartel surplus, internal cartel stability can be assured by standard means. In addition, the basing-point pricing system offers typical punishment strategies, as discussed in Section 2.

${ }^{27}$ The alternative more general blocking condition

$$
\sum_{j=1}^{J} \sum_{v=1}^{V_{j}} \int_{B_{j v}} f(x) T\left(d_{y_{v} x_{i}}\right) d x \leq \sum_{j=1}^{J} \int_{H_{j}} f(x) T\left(d_{l x_{i}}\right) d x
$$

which requires that each candidate collusive base increases the sum total of cartel profits, is less restrictive and requires coordination on a separate profit sharing rule.
} 
Proof. Suppose that $l=y_{j}$, then $\pi_{j}^{a}=\int_{H_{j}} f(x)\left(T\left(d_{y_{j} x_{i}}\right)-T\left(d_{y_{j} x_{i}}\right)\right) d x=0$. Since $\pi_{j}^{c}=\sum_{v=1}^{V_{j}} \int_{B_{j v}} f(x) T\left(d_{y_{v} x_{i}}\right) d x \geq 0$, according to condition (8), $l$ will be blocked as a collusive base candidate by firm $j$.

The area in which always at least one cartel member will block candidate base points, we refer to as the 'blocking zone'. It is found as

$$
\mathcal{B}=\cup_{j=1}^{J} \mathcal{B}_{j}
$$

It follows directly from Proposition 2 that $\mathcal{B}$ contains all of the cartel's plant locations. Figure 2 illustrates the blocking areas and the blocking zone for the geographic market depicted in Figure 1 above.

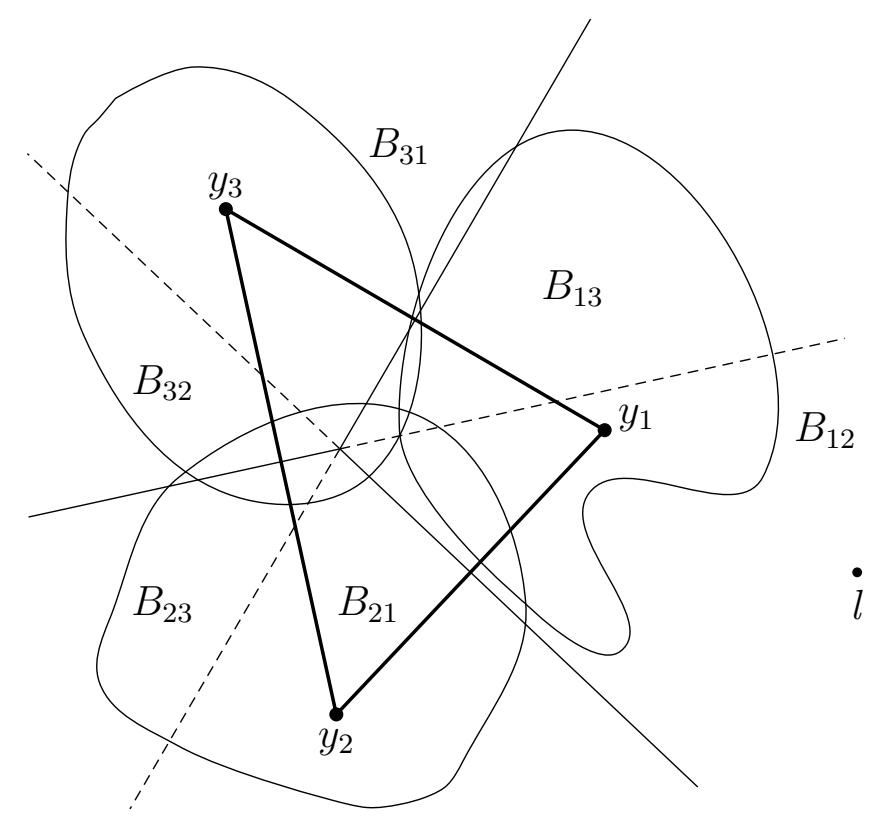

Figure 2: Cloud-shaped blocking zone in regionally isolated market.

The area of candidate collusive base locations blocked by at least one cartel member is amorphous, because while profits are positively related to the distance over which phantom freight is calculated, they need not be linear in distance, which in turn is not linear in the coordinates of locations in Euclidean space. We can further say very little about the blocking zone, beyond that it contains all plant locations of the cartel members. In Figure $2, \mathcal{B}$ comfortably covers the convex hull of firm locations. 
This is not a general property, however, and it can also not straightforwardly be guaranteed by placing specific regularity conditions on the distributions of plant and project locations. ${ }^{28}$

The zone of collusive base point candidates does have natural outer boundaries: no cartel will be able to calculate its orders from the end of the universe. The distance at which the collusive base can be put from the market is restricted, for example, by the maximum willingness to pay of customers, the locations of distant rival firms that are not included in the local cartel, and new entrants being attracted to the area. We do not formalize these restrictions in this paper, since they are not directly relevant for our method of detection.

\section{Detecting Collusive Basing-Point Pricing}

The features of competitive and collusive basing-point pricing identified above allow us to discriminate between competitive and collusive basing-point pricing by a given cluster of firms. After a cartel has chosen its collusive base(s) and demand materializes, trades take place and generate a series of transaction data. To see the difficulty of detecting collusive basing-point pricing in such time-series, consider Table 1. It displays two transaction price patterns per unit of demand, in a regional market with 12 customers and 3 firms, located non-specifically at $(460,460),(440,540)$ and $(650,440)$. Customer locations are indicated in the first column. Transportation costs increase multiplicatively in volume and distance, at a marginal cost of 0.15 per mile per unit. ${ }^{29}$ Marginal costs of production are 50 per unit. There is a fixed cost of 1500 per order. The percentage overcharge per project is given in the last column. ${ }^{30}$

Clearly, prices in the left-hand column are structurally lower than those in the right-hand column. The competitive price series has a mean of 68.2 per unit. The collusive base point prices where calculated from a single collusive base location at $(727,715)$, has a mean of 102.7. Facing just one series of observations, however, that

\footnotetext{
${ }^{28}$ Even if $f(x)$ is unimodal with a mode location $\phi$ around which the firms are distributed at more or less equal distance, and sufficiently steeply bell-shaped with ever fewer customer projects out in the tail ring - which can be interpreted as a high concentration of customers living in a condensed area, and the further away in all directions from this center, the thinner customer projects are spread on the ground - it cannot obviously be assured that a cartel will never choose to locate a single collusive base in their midst, in particular when the circle around the center of the market is large and contains many plants that are at close distance from each other.

${ }^{29}$ That is, $T\left(q_{i}, d_{l x_{i}}\right)=t d_{l x_{l}} q_{i}$ with $t=0.15$.

${ }^{30}$ The overcharge is measured as the percentage unit price increase relative to competitive prices, or $\frac{\text { Price/unit }_{\text {coll }}-\text { Price/unit }_{\text {comp }}}{\text { Price/unit }_{\text {comp }}} \times 100$.
} 


\begin{tabular}{||c||c|c|cc} 
Consumer & Volume & Price/ $_{\text {unit }}$ comp & Price/ $_{\text {unit }_{\text {coll }}}$ & Overcharge (\%) $^{\text {Over }}$ \\
\hline \hline$(500,580)$ & 980 & 70.50 & 91.15 & 29.3 \\
$(630,380)$ & 1070 & 79.58 & 103.72 & 30.3 \\
$(490,520)$ & 1160 & 61.36 & 97.33 & 58.6 \\
$(480,410)$ & 1140 & 71.72 & 110.19 & 53.6 \\
$(520,460)$ & 1260 & 68.16 & 100.46 & 47.4 \\
$(550,410)$ & 820 & 67.49 & 104.73 & 55.2 \\
$(520,420)$ & 900 & 71.40 & 105.72 & 48.1 \\
$(410,510)$ & 1090 & 61.98 & 108.00 & 74.2 \\
$(600,430)$ & 1100 & 72.84 & 98.17 & 34.8 \\
$(540,470)$ & 930 & 68.72 & 97.84 & 42.4 \\
$(470,450)$ & 830 & 66.04 & 107.18 & 62.3 \\
$(430,490)$ & 1010 & 59.13 & 107.38 & 81.6
\end{tabular}

Table 1: Prices per unit and profits under competitive and collusive basing-point pricing.

is, without having the luxury of being able to tell the difference by comparison, it is difficult to see a suspicious pattern. The prices differ across consumers in both regimes. In fact, the example is constructed in such a way that the variance in the competitive price series is exactly equal to the variance in the collusive series - 29.3. Hence, this industry is not likely to surface in a test based on price variance. The cartel overcharge per customer is nevertheless high. The cartel realizes substantial illegal profits over and above the profits under competition, with an average net overcharge of over fifty percent. In the following two subsections, we will show that cartels can indeed systematically exploit the basing-point system to avoid detection by known methods.

\subsection{Variance Screens}

Consider the application of a variance screen for cartels. It tests for local pockets of low variances in transaction prices on the insight that it is difficult for the cartel to create a natural price-variance, because regular price renegotiations, for example in response to cost shocks, are costly and risky. Therefore, prices are fixed for longer periods of time at a sufficiently large margin to cover intermediate cost increases. Several international cartels indeed in hindsight display periods of low variance. Harrington (2004) builds on this to develop a screen and study how cartels subsequently try to avoid it. Abrantes-Metz, et al. (2006) presents a mean-variance screen for clusters of firms colluding, surrounded by competitors. Suspect firms are then those which, within a certain period of time, ask prices with a relatively high mean and a 
low standard deviation.

Obviously, such suspicion can only arise in comparison to some benchmark, be it an earlier period known to have been competitive, a competitive fringe in the same market, or similar firms competing in a different market. In our model of full collusion in a local cluster, such a benchmark is not available. But suppose a threshold value of low price variance somehow does exists. ${ }^{31}$ Then the cartel can strategically locate the collusive base location so as to exactly mimic that variance level and not surface in the test. To see this, consider a world with discretely located customers, $i=1, \ldots, I$ and let $p_{i}$ be transaction price per unit of demand under collusive basing-point pricing from base location $l$ that customer $i$ accepted. That is,

$$
p_{i}=c+\frac{F+T\left(q_{i}, d_{l x_{i}}\right)}{q_{i}},
$$

with the sample mean being

$$
\widehat{p}=\frac{1}{I} \sum_{i=1}^{I}\left(c+\frac{F+T\left(q_{i}, d_{l x_{i}}\right)}{q_{i}}\right) .
$$

The sample variance of a given price series is given by,

$$
\widehat{\sigma}_{p_{i}}^{2}=\frac{1}{I} \sum_{i=1}^{I}\left(p_{i}-\widehat{p}\right)^{2}=\frac{1}{I} \sum_{i=1}^{I}\left(c+\frac{F+T\left(q_{i}, d_{l x_{i}}\right)}{q_{i}}-\widehat{p}\right)^{2},
$$

so that $\widehat{\sigma}_{p_{i}}^{2}$ is a function of the collusive base location $l$. A proper choice of the collusive base location equates the price variance in collusion to that under competition, which is fixed by the locations of the players. It is not difficult to construct examples in which there is a continuum of collusive bases with the same price variance. Figure 3 illustrates such an iso-variance curve.

The figure is a bird's eye-view of the market that generated the data in Table 1. The customer locations are black dots, the triangular area in the middle is the convex hull that connects the three production plant locations. The union of the dashed lined areas around each of the plant locations delineates the blocking zone. A collusive phantom base location outside this zone assures positive net cartel profits for all cartel members. Point $l$ is the collusive base location at $(727,715)$.

The ellipse through $l$ is an iso-variance curve of base locations at which the variance in prices when that location is used to determine collusive offers is identical to

\footnotetext{
${ }^{31}$ Obviously, a known competitive benchmark value for the price mean would be impossible to mimic for the cartel while still making net cartel profits in the long-run.
} 


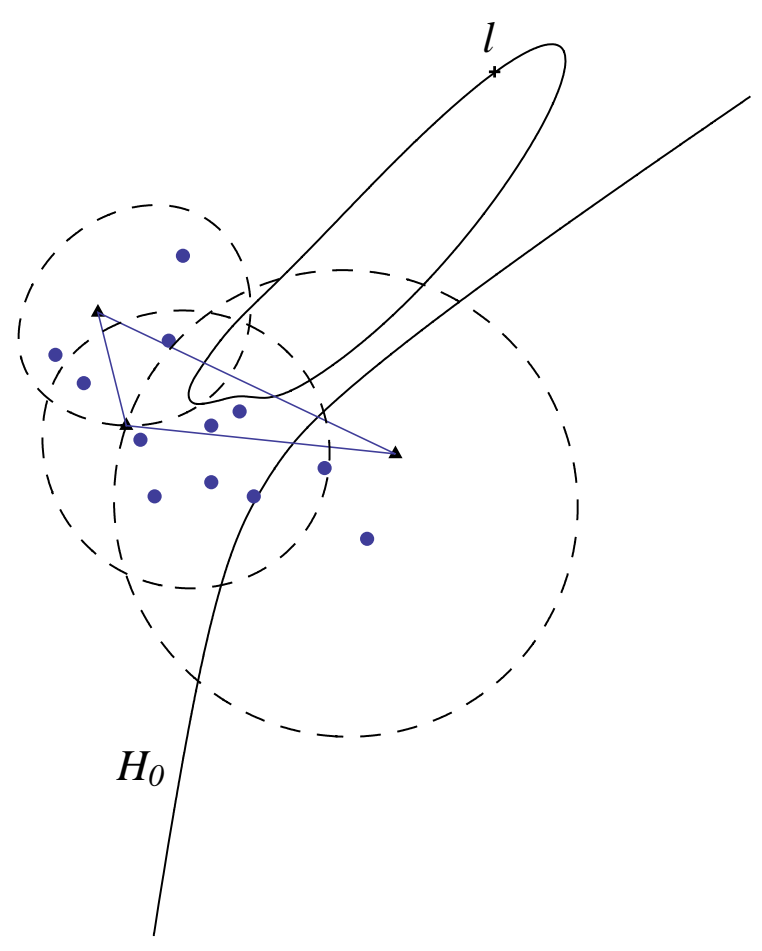

Figure 3: Bird's eye view of base locations in the collusive base zone resulting in a price variance that mimics competition.

the price variance under competition. The part of this iso-variance curve outside the blocking zone collects all collusive base candidates that would generate net expected cartel profits for all firms and escape a variance screen that uses the competitive price variance as a benchmark. On the basis of expected demand $f(x)$, a cartel can analogously determine a set of collusive base locations with an expected variance that would be consistent with competition.

\subsection{Bid-distance Correlation}

A different method for identifying collusive patterns in markets with a geographical dimension uses the distance between the bidding firm and the project location as 
a proxy for production costs. In public procurement auctions for construction of maintenance contracts, one would expect firms to submit higher bids the farther away their plant is located from the project site. Porter and Zona (1993) confirms suspicion of a bidding ring for a Long Island highway construction project in this way. Porter and Zona (1999) reports on evidence of collusion in procurement auctions for school milk in various districts in Ohio, in which the bids of several firms decreased in the distance from their home market to the schools. In Bajari and Ye (2003) the approach is extended to a screen. In first-price sealed bid procurement auctions, the bid-cost ratio is regressed on various explanatory variables, amongst which distance to the project site. Applied to bids for highway maintenance contracts in the late 1990 's in the Mid-West, several firms were found to bid suspiciously relative to their location.

In this paper, we focus on collusive schemes that only leave trails of transaction prices. The basing-point pricing system allows cartels to avoid detection methods that rely on patterns between distance and transaction prices by carefully choosing their collusive bases. To see this for the example of materialized demand above, consider a simple approach to the bid-distance screen, using an ordinary-least-squares test. That is, suppose that a market auditor estimates a relationship between unit transaction prices, $p_{i}$, and the distances between the project and the nearest rival from which the bid would have been calculated in competition, $d_{y_{v} x_{i}}$. That is,

$$
p_{i}=\alpha+\frac{\beta}{q i}+\gamma d_{y_{v} x_{i}}+\varepsilon_{i},
$$

in which $\alpha$ captures marginal costs of production, $\beta$ estimates fixed factors and $\varepsilon_{i} \sim N\left(0, \sigma_{\varepsilon_{i}}^{2}\right)$. In competition, one would expect $\gamma$ to be significantly larger than zero, so that the bids on average increase in the distance between the delivering firm's competitive base and the project location. Therefore, the cartel needs to choose collusive base locations that also return an average positive relationship between these distances and bids. It can do this as follows.

The vector of estimated coefficients is

$$
\left[\begin{array}{l}
\widehat{\alpha} \\
\widehat{\beta} \\
\widehat{\gamma}
\end{array}\right]=\left(\mathbf{X}^{\prime} \mathbf{X}\right)^{-1} \mathbf{X}^{\prime} \mathbf{p},
$$

where $\mathbf{X}$ contains $1^{\prime} s$ in the first column, values $\frac{1}{q_{i}}$ in the second column, and distances $d_{y_{v} x_{i}}$ in the third column. Vector $\mathbf{p}$ contains observed prices. The estimator of the 
standard deviation is,

$$
\widehat{\sigma}_{\widehat{\gamma}}=\sqrt{\frac{\sum e_{i}^{2}}{I-3}\left(\mathbf{X}^{\prime} \mathbf{X}\right)^{-1}},
$$

where $e_{i}^{2}$ are the residuals in the sample.

The cartel can avoid suspicion raised by this test, as long as it makes sure that the null hypothesis $H_{0}: \gamma \geq 0$ is not rejected. $H_{0}$ will be rejected with $95 \%$ confidence if $\widehat{\gamma}<t_{0,05} \times \widehat{\sigma}_{\widehat{\gamma}}$, where the relevant value for $t$ is derived from $\widehat{\gamma} \sim t(I-3)$ and equal to 1.833 in the example of Table 1 above. For all candidate collusive base locations to the left of the curved vertical line in Figure 3, this test cannot reject the null-hypothesis. Note that the area includes the iso-variance curve through $l$, so that the cartel in our example passes the screen based on transaction price variance, as well as the test for bid-distance correlation. As before, a cartel can ex ante set its collusive bases to avoid rejection of $H_{0}$ on expectation. ${ }^{32}$

\section{Tracing the Base}

We have established that it is not obvious how to detect collusive basing-point pricing in historical prices, particularly so when cartels are clever in their choices of collusive base locations. Transaction prices in principle suffice, however, for our test based on the recovery of base locations. To see how this test works, we specialize the general structure of bids under basing-point pricing (3) to

$$
T\left(q_{i}, d_{l x_{i}}\right)=t_{d} d_{l x_{i}}+t_{q} q_{i}+F_{T}
$$

where $t_{d}$ is the marginal cost of transportation per unit of distance and $t_{q}$ per unit of volume, and $F_{T}$ is a fixed component. Assuming a transportation cost structure that is linear in distance and volume implies that the profits from phantom freight per order are independent of the volume of the order. This assumption simplifies our analysis in this section for expositional purposes. Note, however, that our test can handle a variety of other bid-structures as well. ${ }^{33}$

\subsection{Base Recovery}

For now, suppose that for a given sample of transaction data it is known that a single collusive base location was used. Using the definition of distance (2), prices

\footnotetext{
${ }^{32}$ If information on loosing bids is available in addition, cartels can select bases to avoid patterns in those.

${ }^{33}$ This is discussed further in Section 7.
} 
are related to base locations, as follows:

$$
P_{j i}=\overbrace{\left(c+t_{q}\right)}^{\widetilde{c}} q_{i}+\overbrace{\left(F+F_{T}\right)}^{\widetilde{F}}+t_{d} \sqrt{\left(a_{l}-a_{x_{i}}\right)^{2}+\left(b_{l}-b_{x_{i}}\right)^{2}} .
$$

Customer project locations $\left(a_{x_{i}}, b_{x_{i}}\right)$ and transaction data $\left(P_{j i}, q_{i}\right)$ are known, so that equation (16) has five relevant unknowns: $\widetilde{c}=\left(c+t_{q}\right), \widetilde{F}=\left(F+F_{T}\right), t_{d}$, plus the two coordinates of the implied base location $\left(a_{l}, b_{l}\right)$. In principle therefore five independent observations on price-quantity transactions of customers in one and the same base group suffice to determine the base location from which they were calculated. The observations have to be independent in the sense that the consumer locations in each tuple of five observations should not be perfectly aligned. If they are, there exists a mirror point to the applied base, so that the system is not uniquely determined.

In practice, the data on both transactions and project locations will typically be noisy as a result of calculation and measurement errors in production and transportation costs, and possibly missing factors. A least-squares estimation procedure can deal with this. We assume that

$$
P_{j i}=\widetilde{c} q_{i}+\widetilde{F}+t_{d} \sqrt{\left(a_{l}-a_{x_{i}}\right)^{2}+\left(b_{l}-b_{x_{i}}\right)^{2}}+\epsilon_{i},
$$

with $\epsilon_{i} \sim N\left(0, \sigma_{\epsilon_{i}}^{2}\right)$ on the total bid.

We cluster all transaction data per base group, so that all tuples of observations in each data subset correspond to one and the same base location, both in competition and collusion. Since mill and project locations are given, this sorting of the data is straightforward. Let $I_{G_{v}}$ be the number of independent customer projects located in base group $G_{v}$. The base location of base group $G_{v}$ is in principle recoverable if $I_{G_{v}}$ is minimally equal to the number of unknowns in the bid structure. ${ }^{34}$ We can now define the following criterion function

$$
S=\sum_{i=1}^{I_{G v}} e_{i}^{2}
$$

\footnotetext{
${ }^{34}$ In the example given in Section 4, the base group that receives offers calculated from the firm at $(460,460)$ has five customers, that of the firm at $(440,540)$ four, and of the firm at $(650,440)$ three. Using the non-linear specification of transportation costs in footnote 29, which also implies five unknowns, it is only possible to trace two bases in the example: under a competitive regime, the mill locations of the firm at $(460,460)$ and a single collusive base in case of collusion. The system is underdetermined to find the other two competitive bases. Yet, we can just discriminate between competition and collusion on the basis of this information.
} 
where $e_{i}$ are the residuals in the observed transaction data, and determine our estimators to solve

$$
\min _{\widetilde{c}, \widetilde{F}, t_{d}, a_{l}, b_{l}} \sum_{i=1}^{I_{G_{v}}}\left(P_{j i}-\widetilde{c} q_{i}-\widetilde{F}-t_{d} \sqrt{\left(a_{l}-a_{x_{i}}\right)^{2}+\left(b_{l}-b_{x_{i}}\right)^{2}}\right)^{2} .
$$

Figure 4 illustrates the principle of determining $\widehat{l}=\left(\widehat{a}_{l}, \widehat{b}_{l}\right)$ in two dimensions, that is, for given values of $\widehat{c}, \widehat{F}$ and $\widehat{t}_{d}$. In this case, in the absence of noise in the data, three observations per base group suffice to uniquely determine the common base location from which all consumer prices were calculated. Each observation $\left(P_{j i}, q_{i}, a_{x_{i}}, b_{x_{i}}\right)$ defines a circle of locations $l$ around each consumer project location $x_{i}$. The intersection of these three circles is the common base. There is no such perfect intersection when the observations contain noise. Instead each candidate estimate of $\widehat{l}$ implies a difference $e_{i}$ between the distance $\widehat{d}_{i}$ that corresponds with the observation on project $i$ and the distance explained by $\widehat{l}$. Our criterion now is to find $\widehat{l}$ so as to minimize the sum of the squared differences $e_{i}$. It is applied to simultaneously estimate $\widehat{c}, \widehat{F}$ and $\widehat{t}_{d}$ as well.

Problem (19) does not allow for an explicit form for the estimators, nor does it need to have a unique global minimum. ${ }^{35}$ We therefore have to resort to numerical methods of estimation. We use an iterative global search algorithm that is described in detail in Appendix $A$. It benefits from a number of constraints on the parameter spaces. The method is generally determinate and converges to a global minimum.

Each base group data subset that contains a number of independent observations equal to or larger than the number of unknowns (in this case five) returns one base location, so that $J$ bases are recovered as long as the minimum data requirements are met. On the basis of our findings in Section 3, we can subsequently analyze the pattern of recovered bases to see if there is indication of collusive basing-point pricing. A pattern may be indicative of collusion if all firms have used one and the same distant base point. If instead various plant locations are found to have been bases, this would be consistent with competition. In order to further operationalize

${ }^{35}$ To see this, it suffices to note that the second-order own-derivate of $S$ to $a_{l}$, which is

$$
\frac{\partial S}{\partial a_{l} \partial a_{l}}=2 \sum_{i=1}^{I_{G_{v}}} \frac{\left(a_{i}-a_{l}\right)^{2}\left[\frac{1+P_{i}-\widetilde{c} q_{i}-\widetilde{F}+d_{l i}}{d_{l i}}\right]-d_{l i}\left(P_{i}-\widetilde{c} q_{i}-\widetilde{F}+d_{l i}\right)}{\left(a_{i}-a_{l}\right)^{2}+\left(b_{i}-b_{l}\right)^{2}},
$$

can be negative - e.g. when there are small differences in the $a$-coordinates and large differences in the $b$-coordinates. Hence, the $4 \times 4$ Hessian matrix is not positive semidefinite, so that $S$ is not convex. 


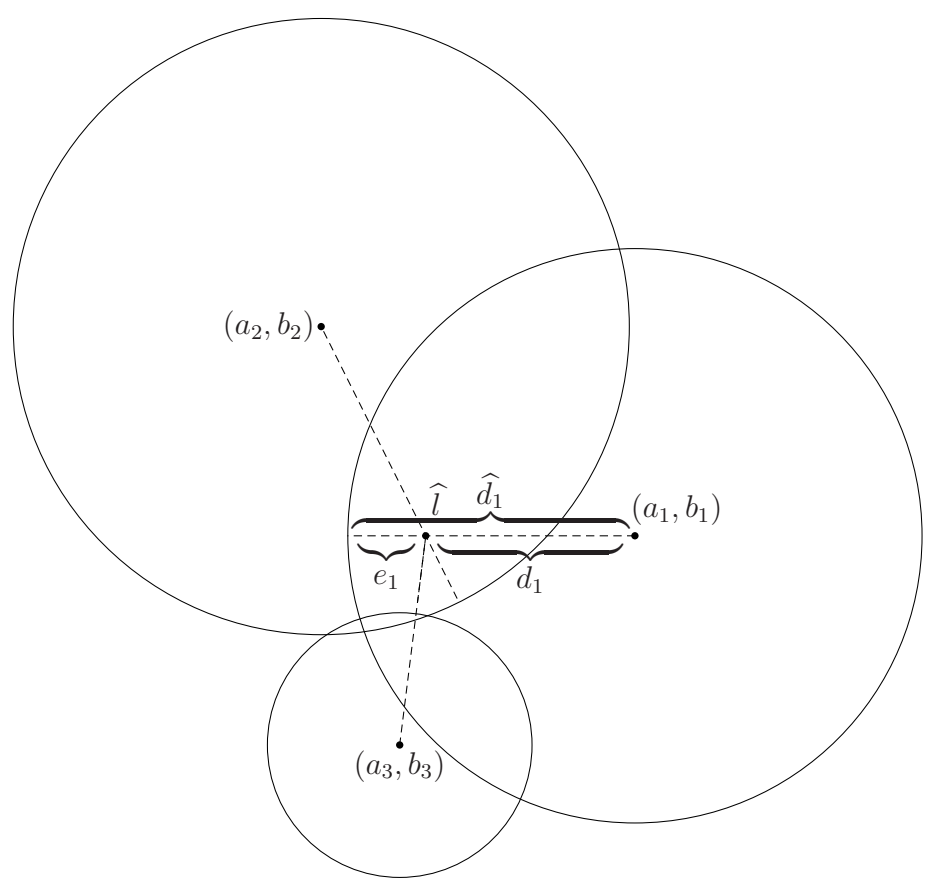

Figure 4: A least-squares point estimator of the base location.

this basic distinction, in the next section we develop a screen for collusive basingpoint pricing.

\section{A Likelihood Measure of Collusion}

Let $N$ be the number of basing points independently found. If producers colluded, their bids were calculated from one and the same base location, so that the bases found will be close together - and sufficiently far away from the cluster of mill locations. In contrast, a competitive world will yield a number of basing points of which the coordinates coincide with the coordinates of firm locations. We therefore take the sample average base location

$$
\bar{a}=\frac{1}{N} \sum_{l=1}^{N} \widehat{a}_{l} \text { and } \bar{b}=\frac{1}{N} \sum_{l=1}^{N} \widehat{b}_{l},
$$


and define the average distance to $(\bar{a}, \bar{b})$ as a measure of the geographical spread in the recovered bases: ${ }^{36}$

$$
\bar{\sigma}=\frac{1}{N} \sum_{l=1}^{N} \sqrt{\left(\left(\widehat{a}_{l}-\bar{a}\right)^{2}+\left(\widehat{b}_{l}-\bar{b}\right)^{2}\right)} .
$$

The general distinct characteristics of competitive and collusive base locations derived above now allow us to discriminate between collusive and competitive basingpoint pricing. First consider the following straightforward result on taking the average of recovered competitive basing points. Let $\mathcal{C}$ denote the convex hull of mill locations, i.e., the smallest convex set containing all mills.

Lemma 1 Without misspecification and noise in the data, under competitive basingpoint pricing, $(\bar{a}, \bar{b}) \in \mathcal{C}$.

Proof. If $\sigma_{\epsilon_{i}}^{2}=0$, by Proposition 1 all discovered bases $\left(\widehat{a}_{l}, \widehat{b}_{l}\right)$ correspond to mill locations and therefore are in $\mathcal{C}$. Since $\mathcal{C}$ is convex, the average of all discovered bases, $(\bar{a}, \bar{b})$, is also located in $\mathcal{C}$.

In addition, since the average basing point under competition generally combines several bases, $\bar{\sigma}>0$ under competition. When applied to a collusive world in which a single basing point has been used, the spread in the recovered bases is equal or very close to zero. In contrast, in case of collusion $(\bar{a}, \bar{b})$ will typically be located outside $\mathcal{C}$.

We use these distinct features to define a measure for the likelihood that there has been collusion in a market under consideration. Using only information on the locations of firms and customers, it is possible to construct the location $(\bar{a}, \bar{b})$ that would theoretically be produced under competition by applying the above described procedure. For that, it is required to determine which firms would be found by the test as a base for its nearest rival in competition - note that these are the firms indicated by the subscript of all base groups $G_{v}$ that contain the minimally required number of independent observations to recover the base. Let this theoretical average competitive base location be $l^{*}$, at $\left(\bar{a}^{*}, \bar{b}^{*}\right)$ with average spread $\bar{\sigma}^{*}$. We then define the following measure

$$
\lambda=\frac{\max _{j} d_{l^{*} y_{j}}}{\bar{\sigma}^{*}}, j=1, \ldots, J
$$

\footnotetext{
${ }^{36}$ We use this measure rather than the standard deviation in distances to $(\bar{a}, \bar{b})$, since the latter is a measure of symmetry, rather than spread. The standard deviation would be zero, for example, for recovered bases that are found evenly distributed on a circle around $(\bar{a}, \bar{b})$, irrespective of the radius of that circle.
} 
where the numerator is the longest of all distances between $\left(\bar{a}^{*}, \bar{b}^{*}\right)$ and the firms on the boundary of $\mathcal{C}$.

Let $S^{\mathcal{C}}$ be the surface area of $\mathcal{C}{ }^{37}$ We construct a circle with radius $\lambda \times \bar{\sigma}$ around the mean recovered base location $(\bar{a}, \bar{b})$ and define the set

$$
\mathcal{L}=\left\{(a, b): \sqrt{(a-\bar{a})^{2}+(b-\bar{b})^{2}} \leq \lambda \times \bar{\sigma}\right\}
$$

Let $S^{\mathcal{L}}$ be the surface area of $\mathcal{L}$.

The likelihood of collusion is now related to the overlap between the convex hull of firm locations and the constructed circle around the recovered mean base location. We introduce the following measure:

$$
L o C=1-\frac{S^{\mathcal{C}} \cap S^{\mathcal{L}}}{S^{\mathcal{C}}}
$$

The value of $L o C$ is always between zero and one. Higher values would be indicative of collusive basing-point pricing. The following proposition defines boundary values.

Proposition 3 Without misspecification and noise in the data, the LoC-measure discriminates perfectly between competitive and collusive basing-point pricing, with:

(i) $L o C=0$ in the case of competition; and

(ii) $L o C=1$ in the case of collusion.

Proof. Suppose $\sigma_{\epsilon_{i}}^{2}=0$. (i) Under competitive basing-point pricing, by Proposition 1 and Lemma $1,(\bar{a}, \bar{b})=l^{*} \in \mathcal{C}$. Furthermore, $\bar{\sigma}=\bar{\sigma}^{*}>0$, so that $S^{\mathcal{C}} \cap S^{\mathcal{L}}=S^{\mathcal{C}}$ by construction. Hence

$$
L o C=1-\frac{S^{\mathcal{C}} \cap S^{\mathcal{L}}}{S^{\mathcal{C}}}=1-\frac{S^{\mathcal{C}}}{S^{\mathcal{C}}}=0 .
$$

(ii) Under collusive basing-point pricing, all mills use the same collusive base $l=\left(a_{l}, b_{l}\right)$, which implies that $(\bar{a}, \bar{b})=\left(a_{l}, b_{l}\right)$ and $\bar{\sigma}=0$. Hence, $\lambda \times \bar{\sigma}=0$, so that $S^{\mathcal{L}}=0$, which yields

$$
L o C=1-\frac{S^{\mathcal{C}} \cap S^{\mathcal{L}}}{S^{\mathcal{C}}}=1-\frac{0}{S^{\mathcal{C}}}=1 .
$$

Note that typically $l$ is a distant location. In a punishment phase, however, it is a single firm location.

\footnotetext{
${ }^{37}$ Note that firm locations should not all be aligned for $\mathcal{C}$ to have a positive surface area. This implies that $J \geq 3$ for the test to work.
} 
Obviously, this perfect discrimination result only holds in the absence of noise in the data or misspecification errors. One way to apply the $L o C$-measure when there are such imperfections is to raise a red flag of likely collusion on an industry when the value of $L o C$ is found to be above a certain absolute level, for example 0.5. Alternatively, the measure can be used to design a hypothesis test, also using the bid sample variance. To what extent measurement errors affect the usefulness of our test statistic depends on the structure and the size of the noise. Obviously, if the actual bid structure is different from the structure used to recover the bases, the error terms are not normally distributed and the test will be structurally off. A misspecification test with alternative bid structures could help to identify such problems. ${ }^{38}$

Truly white noise on the bid structure, which may for example have resulted from miscalculations by the firms or measurement errors, need not affect the power of the $L o C$-test in practice, provided it is not too strong. White noise will dislocate $(\bar{a}, \bar{b})$ from $l^{*}$ under competition, so that $S^{\mathcal{L}}$ generally no longer covers $S^{\mathcal{C}}$ and $L o C$ values are larger than zero. Imperfect observations will also make that $\bar{\sigma}$ is positive under collusion. Multiplied by $\lambda$, this potentially results in a substantial surface area $S^{\mathcal{L}}$. When the collusive base is inside or not too far away from $\mathcal{C}$, this may result in partial overlap, leading to an $L o C$ value that is smaller than 1, despite that fact that the mills are in fact colluding. Generally, however, $\bar{\sigma}^{2}$ converges to zero when the number of independent observations per base group becomes sufficiently large. In addition, a wider spread of customer locations and firm plants makes for a more accurate location of the collusive base, in particular when it is far away from the market. Also the blocking zone will often embed the hull and provide a safety belt against large overlap.

Using the method described in Appendix A, in Figure 5, we plot the value of $L o C$ against $\sigma_{\epsilon_{i}}$ in equation (17) for two types of geographic markets: one in which the cartel locates the collusive base far away from all members, and one in which the cartel can profitably place the base inside the convex hull of firm locations. ${ }^{39}$ This analysis reveals that the $L o C$-measure remains a robust tool also when the size of the random noise in the price data increases.

In the upper two panels, 3 firms located at $(460,460),(440,540)$ and $(650,440)$, as in the example above, produce with marginal costs of 5, fixed costs of 1500 and transportation costs equal to 1 . They serve 25 customers per base group. ${ }^{40}$ There

\footnotetext{
${ }^{38}$ Possible directions in which to develop such specification tests are briefly discussed in Section 7.

${ }^{39}$ In these simulations, we have fixed $t_{d}=1$, the true value of common transportation costs. See Appendix $A$.

${ }^{40}$ The coordinates of these 75 consumer locations are drawn from two normal distributions, each with a mean equal to the sample mean firm coordinate and a variance equal to the sample variance
} 

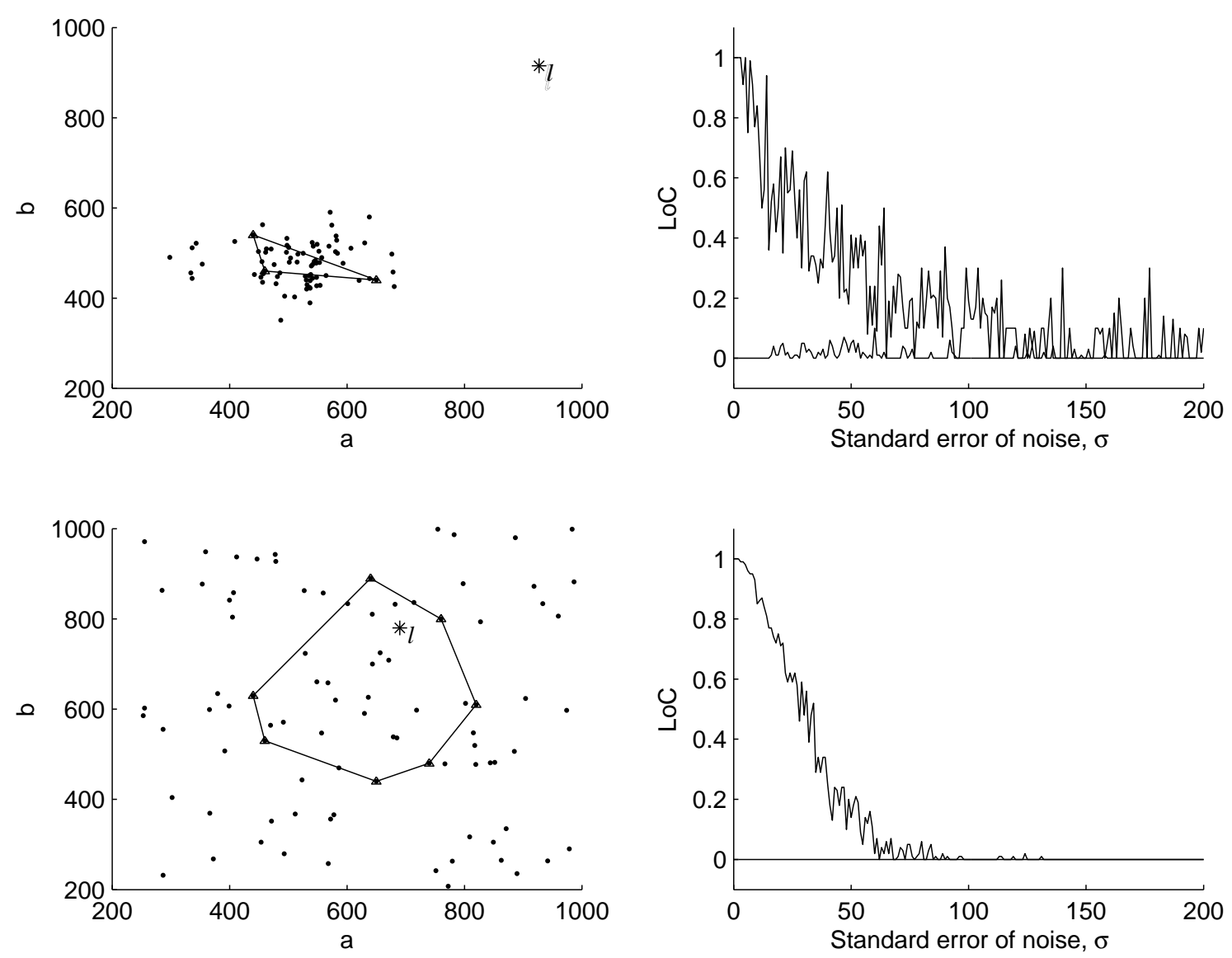

Figure 5: Robustness of the $L o C$-measure as an enforcement tool for two examples of collusive basing-point pricing.

is some variability in demand at each project location, $q_{i} \sim N(1000,50)$, capped at zero. $^{41}$ The upper-left graph provides a bird's eye view of the market. The upperright panel plots the average $L o C$ calculated over 10 drawings of price bids for each value for the standard deviation. Average profits under the cartel are substantial, ranging from 5 to 25 times competitive profits. The upper line shows the $L o C$ measure under collusion falling from 1, where the mean collusive overcharge was

\footnotetext{
in the firm locations.

${ }^{41}$ The size of this standard error of demand is somewhat smaller but comparable to that in the example in Section 4, Table 1 above.
} 
$7.31 \% .{ }^{42}$ The lower line going from 0 is the $L o C$-measure under competition. The figure shows that the measure can discriminate roughly for a standard deviation of up to 100 from an average collusive price bid of roughly 7000 .

The lower two panels of Figure 5 are simulations with a constructed example of 7 firms that are located in a circle - as seen in the lower-left graph - in such a way that they can profitably collude with a base location in their midst. ${ }^{43}$ All mills produce with a marginal costs of 5, fixed costs of 1500 and transportation costs of 1 . The cartel profits of each firm are positive, ranging between a few hundred and a few thousand, but the mean cartel overcharge is modest, 1.97\%-obviously, there are more attractive collusive base candidates outside the hull. Each of the 7 base groups contains 25 customer projects with variable demand, as in the previous example. ${ }^{44}$ The $L o C$-measure under competition is a flat line. Under collusion, the $L o C$-value appears no longer to discriminate roughly at around $\sigma_{\epsilon_{i}}=60$ from an average collusive price bid of about $7000 .{ }^{45}$

These simulations have been generated with a computer program that uses a step grid search. Its structure is explained in Appendix $A$. The software can be operationalized to use the $L o C$-measure as a screen for anticompetitive behavior in large data sets - in particular, it would need to be extended to also independently estimate $t_{d}$. The program, BaseLocator ${ }^{\circledR}$, needs a structured data file with the individual mill and customer project locations, and for each project location the volume of trade and the price at which it was ordered. For a given structure of transportation costs - so far the linear specification (15), but alternative structures are possible as well - the program returns the likelihood of collusion. The software could be used as a screen in the sense that suspiciously high values of $L o C$ could be candidates for targeted investigations. A deeper investigation can be entered, for example, when the null hypothesis $H_{0}: L o C=0$ is rejected at a set confidence level.

\footnotetext{
${ }^{42}$ The collusive base was $(927,915)$ and transportation costs are linear in distance and volume in these simulations. From each base group there are 25 observations on transactions. The plotted lines in the figure are the average of 10 random price series under each regime. Consumer locations remained fixed over these runs. The mean transaction price in competition was 6655.94 and in collusion 7141.34.

${ }^{43}$ These firm locations are $(440,630),(640,890),(820,610),(650,440),(740,480),(760,800)$ and $(460,530)$.

${ }^{44}$ The coordinates of these 175 consumer locations are drawn from two normal distributions, each with a mean equal to the sample mean firm coordinate and a variance equal to three times the sample variance in the firm locations to obtain a wider spread.

${ }^{45}$ The collusive base here was $(690,780)$. The mean transaction price in competition was 6917.49 and in collusion 7053.56 .
} 


\section{Concluding Remarks}

Collusive basing-point pricing is an elusive form of price conspiracy. The system is clever, easy to implement and it leaves few traces. Therefore, collusive basing-point pricing is difficult to tell apart from genuine competition by conventional means. Where a cartel is suspected to have abused basing-point pricing, it may be difficult to prosecute for lack of hard evidence. We propose to test for collusive basing-point pricing by recovering the base(s) used in calculating prices, using order volumes, transaction prices and customer locations. By comparing the implied base location(s) with the locations of the production mills, the test discriminates between competitive and collusive basing-point pricing. The method can be applied as a screen in industries that traditionally use delivered pricing systems. It can help to detect cartels in a relatively simple and inexpensive way, that is both non-invasive for innocent firms and hard to beat for cartels. When a cartel was found to have abused the basing-point system, our method can be used to estimate antitrust damages. A software that operationalizes the proposed method is outlined.

The next step for us would be to apply our method to actual data from industries known or suspected to have used collusive basing-point pricing. Although the early antitrust cases involving basing-point pricing mentioned in the introduction were obviously more complex than our basic model, they appear to be broadly consistent with our analysis. We leave the identification and consistent collecting of suitable data for future research, but we can sketch some directions for analysis. ${ }^{46}$

In the U.S. steel example, Pittsburgh-Plus was first used in 1880, when the dominant producer Carnegie Steel, located in Pittsburgh, commonly priced with several smaller producers in eastern Pennsylvania and New Jersey from Pittsburgh to all destinations. ${ }^{47}$ For Carnegie Steel, which faced no competitors west of it, the common base assured that it could deliver steel profitably in the whole of the United States. Chicago mills, which had a limited capacity, benefitted from phantom freight. The system broke down at around 1920, when producers sprang up more western and some Chicago mills had increased their capacity and started to undercut the system. Our test would in principle be able to identify Pittsburgh as a common single base point and be useful in estimating realized cartel overcharges.

In Cement Institute, collusion was facilitated first by a single basing-point system. The cartel later changed to a complex multiple basing-point system after the "Cement

\footnotetext{
${ }^{46}$ In order to be able to confront our method with real transaction data, the numerical estimation method described in Appendix $A$ would first need to be extended to determine $\widehat{t}_{d}$ as well. This slightly increases data and computational requirements.

${ }^{47}$ See Commons (1924), Marengo (1955) and Greenhut (1987).
} 
Institute" was established in 1929 to publish and distribute 'freigh rate books' from which cartel members were to calculate their bids. ${ }^{48}$ Collusive bases would vary over time and often coincide with production locations. In 1937, for example, of the 165 mills in the cartel, 79 acted as a basing point, against 8 additional distant basing points. ${ }^{49}$ This may have been related to the fact that cement could not be shipped over such long distances as steel could, so that the Institute in fact administered a number of locally isolated cartel clusters. It has also been suggested that the complexity of using multiple basing points helped to conceal the collusive nature of the system. ${ }^{50}$ Our method could be employed to try to identify clusters of plants that used a common base for certain periods of time in local cartel rings.

In Softwood-Plywood, there appear to have indeed been two locally isolated clusters. Prior to 1963, plywood, a building material, could be produced almost exclusively in the coastal area of the Pacific Northwest. The development of lamination techniques in the early 1960's made production possible in the south-eastern part of the United States. Beginning in 1963, Southern plywood production grew steadily and by the middle part of the 1970's more than fifty Southern plants accounted for roughly 40 percent of the plywood produced in the U.S. The incumbent northern firms had long used Portland, Oregan as a common base in their midst from which they each charged near competitive delivered prices. Until the FTC issued a cease-and-desist order in 1977, and the industry adopted mill pricing, the southern entrants managed to maintain Portland as a single base. Consumers purchasing southern plywood, wherever located, paid delivered prices based on rail freight charges from Portland, regardless of the actual mode of transportation utilized or the origin of the plywood shipment. The southern cluster profited, as Gilligan (1992) establishes. We could use our method to establish the Portland base and estimate antitrust overcharges.

We offer some ideas for extensions of the analysis in the text. For illustrative purposes, in Section 5 we have assumed away any interaction in costs between distance and quantity. However, our test can in principle deal with a variety of transportation technologies, as long as they are continuous. ${ }^{51}$ Note, however, that it would introduce a specification error if the true structure of transportation costs were to be different from the one assumed in the procedure. This will generally result in the

\footnotetext{
${ }^{48}$ See Loescher (1959).

${ }^{49}$ See Machlup (1949).

${ }^{50}$ See Greenhut (1987).

${ }^{51}$ Alternatively, freight could be organized in integer units of a given volume, say the cargo hull of a truck or airplane, so that the transportation costs of a total volume shipping are given in a multiple of this minimal volume. Note the transportation costs can in principle decrease in distance, as well. This violates Assumption 2, but would still allow base recovery.
} 
identification of locations that are systematically off base, so that the test may no longer discriminate. It is straightforward to program a choice of transportation cost specifications. The software could also be set up to try a number of non-linear specifications for the best fit. This could be done on the basis of a traditional LS-criterion, or using a criterion of lowest sample variance.

In order to bring our analysis to data successfully, we would probably need to extend it with differences in productive efficiency and capacity constraints, so as to capture all motives to apply basing-point pricing in some of these cases. Also, we have so far worked under the assumption that there is a known and isolated local cluster of mills involved in the cartel. As said, if outside competitors exist-be it individual firms or separate clusters that each formed their own local cartel ring - their plant locations are natural collusive bases. Obviously, for the above described basic version of our test to work properly, it must be applied to a correctly identified cartel cluster that does not include fringe competitors. ${ }^{52}$ Should competitors mistakenly be included, the test would use too wide a convex hull of firm locations. Moreover, if one of the nearest distant rivals has been the collusive base for the cartel, the test in principle recovers its mill location as a single base. Since this base location is found with a small spread, as well as likely on the boundary of the hull, the software would in principle still return a high value of the $L o C$-measure.

Our basic test has to be applied with caution when there are multiple clusters of firms that each collude independently. ${ }^{53}$ Such distant clusters that are mistakenly taken together as one cartel in the application of our test can lead to a high sample variance and to a low $L o C$-measure. Note, however, that it is really only the straightforward application of the $L o C$-measure which causes this problem. Suspicious multiple basing-points systems could still be spotted if instead the entire pattern of recovered bases would be studied by hand, rather than automatically processed in the proposed screen. Furthermore, a relatively straightforward extension of the algorithm could test recursively for the presence of separate collusive clusters in the transaction data. Starting from all firms, the method could in principle find the best fit of local clusters of firms with a common collusive base. Such an approach would determine the boundaries of (local) cartels with less than all competitors in the relevant market. We leave such collusive cluster analysis for further research.

Caution must also be applied in the interpretation of the $L o C$-values when the structure of the data does not result from the use of a single collusive basing point.

\footnotetext{
${ }^{52}$ Conceptually, including competitors in an alledged cartel cluster is comparable to mistakingly using unrelated crime scenes in the geographical profile of a serial offender.

${ }^{53}$ See Levy and Reitzes (1993).
} 
If the data cover a long period of time, they may include bids formulated under collusive as well as competitive regimes. If the period covers a punitive phase (or phases), the vector of recovered bases includes the location (s) of firm(s) that were punished. ${ }^{54}$ This will result in a large variance and test surface area, albeit around an average base location that is likely to be away from the plant locations. A similar measurement error would occur if the cartel formed during the recorded time-series. Apart from being quite coincidental, positive values of $L o C$ would often still single these markets out for closer inspection. In general, our test would better not be applied when the intervals between bids are large.

A related problem arises when cartels have applied different distant collusive bases over the sample period. If more than one collusive base, located at different quarters around the cluster of firms, have generated a sample that is treated as if generated from one base, the sample variance is likely to be erroneously large and the sample mean may be close to the center of the market. A cartel that would understand this effect on the test could deliberately rotate its collusive bases in an attempt to avoid discovery. ${ }^{55}$ In addition, this could help to allocate cartel profits more evenly between the members. Transaction data could in principle be scrutinized for such avoidance patterns, thus forcing the cartel in ever more complex and costly agreements with associated difficulties of cheating and monitoring.

Cartels could also try to avoid a basic version of our test by using a somewhat altered collusive bid formula, in which each cartel member adds the collusive phantom freight based on the distance between the collusive base and the customer project to the phantom freight it would charge in competition, which is based on the customer's distance to the mill's nearest rival. This collusive bid structure is still relatively straightforward. It has as a benefit over the common rule discussed in the text that it retains the differences in quoted prices that would be observed under competition when also all distant firms bid their true transportation costs. The system furthermore creates a natural division of the market in home markets, as all competitive bids are marked up by the same amount. The added variability in the bids would make it somewhat more difficult to trace, yet the software can straightforwardly be extended to test for this specific alternative bid structure. In addition, new plant

\footnotetext{
${ }^{54}$ Greenhut (1987) warns for this where he points out that sellers can establish "... difficult to evaluate variants of multiple base point system." This leads the author to conclude against the common belief at the time that: "To assert ... that the Basing Point system is ... on its way out of use in the United States would ... be a stronger inference than one can soberly make." (op.cit., pp.202-3).

${ }^{55}$ In reference to the geographical profiling methods discussed in Section 1, this would be similar to a serial killer that outsmarts the sheriff's software by well-placing the bodies of its victims around somebody else's address.
} 
location choices and entry decisions may endogenize the presence of basing-point screens - which, in turn, may provide grounds for additional tests on location patterns typical for collusion. In any event, for industries that aspire to conspire, the need to try to avoid sophisticated detection methods will at a minimum make it more complex - and thus less attractive - to collude.

\section{References}

[1] Abrantes-Metz, R.M., L.M. Froeb, J. Geweke and C.T. Taylor (2006), "A Variance Screen for Collusion," International Journal of Industrial Organization, 24, 467-486;

[2] Bajari, P.L. and L. Ye (2003), "Deciding Between Competition and Collusion," Review of Economics and Statistics, 85, 971-989;

[3] Benson, L., M.L. Greenhut and G. Norman (1990), "On the Basing-Point System," American Economic Review, 80, 584-588;

[4] Cabou, C. G., D.D. Haddock and M.H. Thorne (1992), "An Analytic History of Delivered Price Litigation: Do Courts Properly Distinguish Rivalrous from Collusive Instances," Economic Inquiry, 30, 307-321;

[5] Canter, D. (2003), Mapping Murder: The Secrets of Geographical Profiling, Virgin Publishing;

[6] Carlton, D. W. (1983), "A Reexamination of Delivered Pricing," Journal of Law and Economics, 26, 51-70;

[7] Clark, J.M. (1943), "Imperfect Competition Theory and Basing-Point Problems," American Economic Review, 33(2), 283-300;

[8] Clark, J.M. (1949), "The Law and Economics of Basing Points: Appraisal and Proposals," American Economic Review, 39(2), 430-447;

[9] Commons, J.R. (1924), "The Delivered Price Practice in the Steel Market," American Economic Review, 14, 505-519;

[10] Espinosa, M.P. (1992), "Delivered Pricing, FOB Pricing, and Collusion in Spatial Markets," RAND Journal of Economics, 23(1), 64-85; 
[11] Federal Trade Commission, "Findings, Opinions and Orders in the Matter of Boise Cascade Corporation, et al.," Federal Trade Commission Decisions, January 1978, 91, 1-111;

[12] Gilligan, T.W. (1992), "Imperfect Competition and Basing-Point Pricing: Evidence from the Softwood Plywood Industry," American Economic Review, 82, 1106-1119;

[13] Greenhut, M.L. (1981), "Spatial Pricing in the USA, West Germany, and Japan," Economica, 48, 79-86;

[14] Greenhut, M.L. (1987), "Basing point system," in: J. Eatwell, M. Milgate and P. Newman (eds.), The New Palgrave: A Dictionary of Economics, Vol. 1, Stockwell Press, New York;

[15] Haddock, D.D. (1982), "Basing-Point Pricing: Competitive vs. Collusive theories," American Economic Review, 72, 289-307;

[16] Haddock, D.D. (1990), "On the Basing-Point System: Comment," American Economic Review, 80, 957-962;

[17] Harrington, J.E., Jr. (2004), "Cartel Pricing Dynamics in the Presence of an Antitrust Authority," RAND Journal of Economics, 35, 651-673;

[18] Harrington, J.E., Jr. (2008), "Detecting Cartels," in: P. Buccirossi (ed.), Handbook in Antitrust Economics, MIT Press, Cambridge, MA;

[19] Hay, G.A. (1999), "Practices that Facilitate Cooperation: the Ethyl Case," in: J. Kwoka and L. White (eds.), The Antitrust Revolution, 3rd ed., Oxford University Press, New York;

[20] Karlson, S.H. (1990), "Competition and Cement Basing Points: F.O.B. Destination, Delivered from Where?," Journal of Regional Science, 30, 75-88;

[21] Kaysen, C. (1949), "Basing Point Pricing and Public Policy," Quarterly Journal of Economics, 63, 289-314;

[22] Levenstein, M.C. and V.Y. Suslow (2006), "What Determines Cartel Success?," Journal of Economic Literature, 44(1), 43-95;

[23] Levy, D.T. and J.D. Reitzes (1993), "Basing-Point Pricing and Incomplete Collusion," Journal of Regional Science, 33, 27-35; 
[24] Loescher, S.M. (1959), Imperfect Collusion in the Cement Industry, Cambridge, MA: Harvard University Press;

[25] Loescher, S.M. (1980), "Economic Collusion, Civil Conspiracy, and Treble Damage Deterrents: The Sherman Act Breakthrough with Southern Plywood," Quarterly Review of Economics and Business, 20, 6-35;

[26] Machlup, F. (1949), The Basing-point System, Philadelphia, The Blakiston Company;

[27] Marengo, L.M. (1955), "The Basing Point Decisions and the Steel Industry," American Economic Review, 45(2), 509-522;

[28] McAnney, J.W. (1991), "The Justice Department's Crusade Against PriceFixing: Initiative or Reaction," Antitrust Bulletin, 521-542;

[29] Porter, R.H. (2005), "Detecting Collusion," Review of Industrial Organization, 26, 147-167;

[30] Porter, R.H. and J.D. Zona (1993), "Detection of Bid Rigging in Procurement Auctions," Journal of Political Economy, 1001, 518-538;

[31] Porter, R.H. and J.D. Zona (1999), "Ohio School Milk Markets: An Analysis of Bidding," RAND Journal of Economics, 30(2), 263-288;

[32] Rossmo, D.K. (1999), Geographic Profiling, CRC Press, Baton Rouge, FL;

[33] Scherer, F.M. and D. Ross (1990), Industrial Market Structure and Economic Performance, 2nd edition, Boston, Houghton Mifflin Company;

[34] Schinkel, M.P., J. Tuinstra and J. Rüggeberg (2008), "Illinois Walls: How Barring Indirect Purchaser Suits Facilitates Collusion," RAND Journal of Economics, 39(3), 683-698;

[35] Smithies, A. (1942), "Aspects of the Basing-Point System," American Economic Review, 32, 705-726;

[36] Smithies, A. (1941), "Monopolistic Price Policy in a Spatial Market," Econometrica, 9(1), 63-73;

[37] Soper, J.B., G. Norman, M.L. Greenhut and B.L. Benson (1991), "Basing Point Pricing and Product Concentration," Economic Journal, 101, 539-556; 
[38] Stigler, G.J. (1949), "A Theory of Delivered Price Systems," American Economic Review, 39, 477-489;

[39] Thisse, J-F. and X. Vives (1988), "On the Strategic Choice of Spatial Price Policy," American Economic Review, 78, 122-137;

[40] Thisse, J-F. and X. Vives (1992), "Basing-Point Pricing: Competition versus Collusion," Journal of Industrial Economics, 40, pp. 249-260. 


\section{A BaseLocator ${ }^{\circledR}$}

We have operationalized our proposed cartel screen in a simple topographic detection routine in Delphi $5^{\circledR}$. Here we illustrate the logic of the algorithmic steps taken in the software. Below we give the main program with the key subroutines TracingBP, which traces the base using function SumOfSquares, and EstimateLstatistic, which calculates the value of $L o C .{ }^{56}$

\section{A.1 Steps to Trace the Base}

Input is a structured data file that has a column of individual mill locations, and a column of individual customer project locations with the volume of trade and the transaction price per project. Base tracing consists of three main steps: data sorting, base tracing, and calculation of the $L o C$-measure.

In the first step, the data are sorted. All transaction data $\left(P_{i}, q_{i}\right)$ are grouped by base group, using the information on project site locations. Those combinations of project locations that are aligned are disregarded as not independent - but this is a rare occasion. All base groups with less independent observations than the number of unknowns are ignored - this small sample problem would normally not need to appear. In the simulations presented in the text, we have assumed $t_{d}=1$ is known for analytical convenience, so that the minimally required number of independent observations per base group is four. What remains is $N$ sets of independent observations, $N \leq J$.

In the second step, each constructed set of observations $l=1, \ldots N$ is used to recover $\widetilde{c}, \widetilde{F}$ and base location used for the base group considered, $\left(\widehat{a}_{l}, \widehat{b}_{l}\right)$. For this, the specification of $T\left(q_{i}, d_{l i}\right)$ is crucial. The software would in principle allow for a variety of specifications of $T\left(q_{i}, d_{l i}\right)$ - for the user to choose from, or for the program to find the best fit amongst. In the present version, transportation costs are linear in distance and volume, and including a fixed component, as in equation (15) in the text.

In a bounded area - that we determine as the size of the convex hull area of customer projects locations, extended with twice that size in all directions - the program step-searches in steps of 20 in the grid for the specification of $\left(\widetilde{c}, \widetilde{F},\left(\widehat{a}_{l}, \widehat{b}_{l}\right)\right)$ that returns the lowest $S$ value. ${ }^{57}$ To be most computationally efficient, we first use

\footnotetext{
${ }^{56}$ The other subroutines called in the program are less insightful and rather lenghty. They are available upon request from the authors.

${ }^{57}$ For the simulations underlying Figure 5, the grid dimensions were such that on average roughly
} 
the information of the partial first-order conditions to problem (19):

$$
\begin{aligned}
\frac{\partial S}{\partial \widetilde{c}} & =-2 \sum_{i=1}^{I_{G_{v}}} q_{i}\left(P_{i}-\widetilde{c} q_{i}-\widetilde{F}-\sqrt{\left(a_{l}-a_{x_{i}}\right)^{2}+\left(b_{l}-b_{x_{i}}\right)^{2}}\right)=0, \text { and } \\
\frac{\partial S}{\partial \widetilde{F}} & =-2 \sum_{i=1}^{I_{G_{v}}}\left(P_{i}-\widetilde{c} q_{i}-\widetilde{F}-\sqrt{\left(a_{l}-a_{x_{i}}\right)^{2}+\left(b_{l}-b_{x_{i}}\right)^{2}}\right)=0
\end{aligned}
$$

to obtain

$$
\begin{aligned}
\widetilde{c} & =\frac{\sum_{i=1}^{I_{G v}} q_{i}\left(P_{i}-\widetilde{F}-d_{l i}\right)}{\sum_{i=1}^{I_{G v}} q_{i}^{2}}, \text { and } \\
\widetilde{F} & =\frac{\sum_{i=1}^{I_{G v}}\left(P_{i}-\widetilde{c} q_{i}-d_{l i}\right)}{I_{G_{v}}} .
\end{aligned}
$$

where $d_{l i}=\sqrt{\left(a_{l}-a_{x_{i}}\right)^{2}+\left(b_{l}-b_{x_{i}}\right)^{2}}$. yields

Using the averages $\bar{P}=\frac{\sum_{i=1}^{I_{G v}} P_{i}}{I_{G_{v}}}, \bar{q}=\frac{\sum_{i=1}^{I_{G v}} q_{i}}{I_{G_{v}}}$ and $\bar{d}_{l}=\frac{\sum_{i=1}^{I_{G v}} d_{l i}}{I_{G_{v}}}$, some manipulation

$$
\begin{aligned}
\widetilde{c} & =\frac{\frac{1}{I_{G_{v}}} \sum_{i=1}^{I_{G v}} q_{i}\left(P_{i}-d_{i}\right)-\bar{q}\left(\bar{P}-\bar{d}_{l}\right)}{\frac{1}{I_{G_{v}}} \sum_{i=1}^{I_{G_{v}}} q_{i}^{2}-\bar{q}^{2}}, \text { and } \\
\widetilde{F} & =\bar{P}-\left(\frac{\frac{1}{I_{G_{v}}} \sum_{i=1}^{I_{G_{v}}} q_{i}\left(P_{i}-d_{i}\right)-\bar{q}\left(\bar{P}-\bar{d}_{l}\right)}{\frac{1}{I_{G_{v}}} \sum_{i=1}^{I_{G_{v}}} q_{i}^{2}-\bar{q}^{2}}\right) \bar{q}-\bar{d}_{l} .
\end{aligned}
$$

Plugging these expressions for $\widetilde{c}$ and $\widetilde{F}$ into the criterion function (19), we obtain

$$
S=\sum_{k=1}^{I_{G_{v}}}\left(P_{k}-\bar{P}+\bar{d}_{l}-d_{l k}+\left[\bar{q}-q_{k}\right]\left(\frac{\frac{1}{I_{G_{v}}} \sum_{i=1}^{I_{G V}} q_{i}\left(P_{i}-d_{i}\right)-\bar{q}\left(\bar{P}-\bar{d}_{l}\right)}{\frac{1}{I_{G_{v}}} \sum_{i=1}^{I_{G_{v}}} q_{i}^{2}-\bar{q}^{2}}\right)\right)^{2}
$$

for which we are to find the value(s) for $\left(\widehat{a}_{l}, \widehat{b}_{l}\right)$ that return(s) the lowest $S$-value.

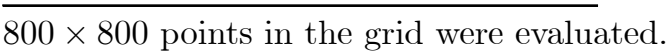


Inside the set search area, the value of $S$ is now determined for each combination $(a, b)$. The program stores the $S$-value and overwrites it whenever a further grid-point yields a lower value. This is our candidate basing point.

In the third step, the base locations found are translated into the $L o C$-measure. The program determines the convex hull of firm locations and its surface. It determines $\lambda$ according to definition (20) on the basis of the theoretical competitive mean base point and variance, using project and mill locations only. Since the data are sorted per base group, in competition each mill would be found only once. The theoretical competitive mean base point therefore is the unweighted mean of the mill locations - excluding mills that would have been used by rivals with too few transactions to triangulate (see the first step). The program subsequently calculates the mean recovered base location and the 'distance spread-circle' around it. The intersection of these two areas gives the $L o C$-measure, a number between zero and one. The insection is estimated by determining for each discrete point in a $100 \times 100$ grid whether it is in both $\mathcal{L}$ and $\mathcal{C}$, or in $\mathcal{L}$ and not in $\mathcal{C}$.

As output, the program returns the name of the data set used, a location $l^{*}$ referred to as the center of the convex hull for reference, the value of $\lambda$, the sample mean base, the sample mean variance, the parameters of the bid structure estimated (assuming $t_{d}=1$ ), and the value of the $L o C$-measure. High values of $L o C$ are indicative of collusion, in particular when supported by a small sample variance.

\section{A.2 Kernel of the Software}

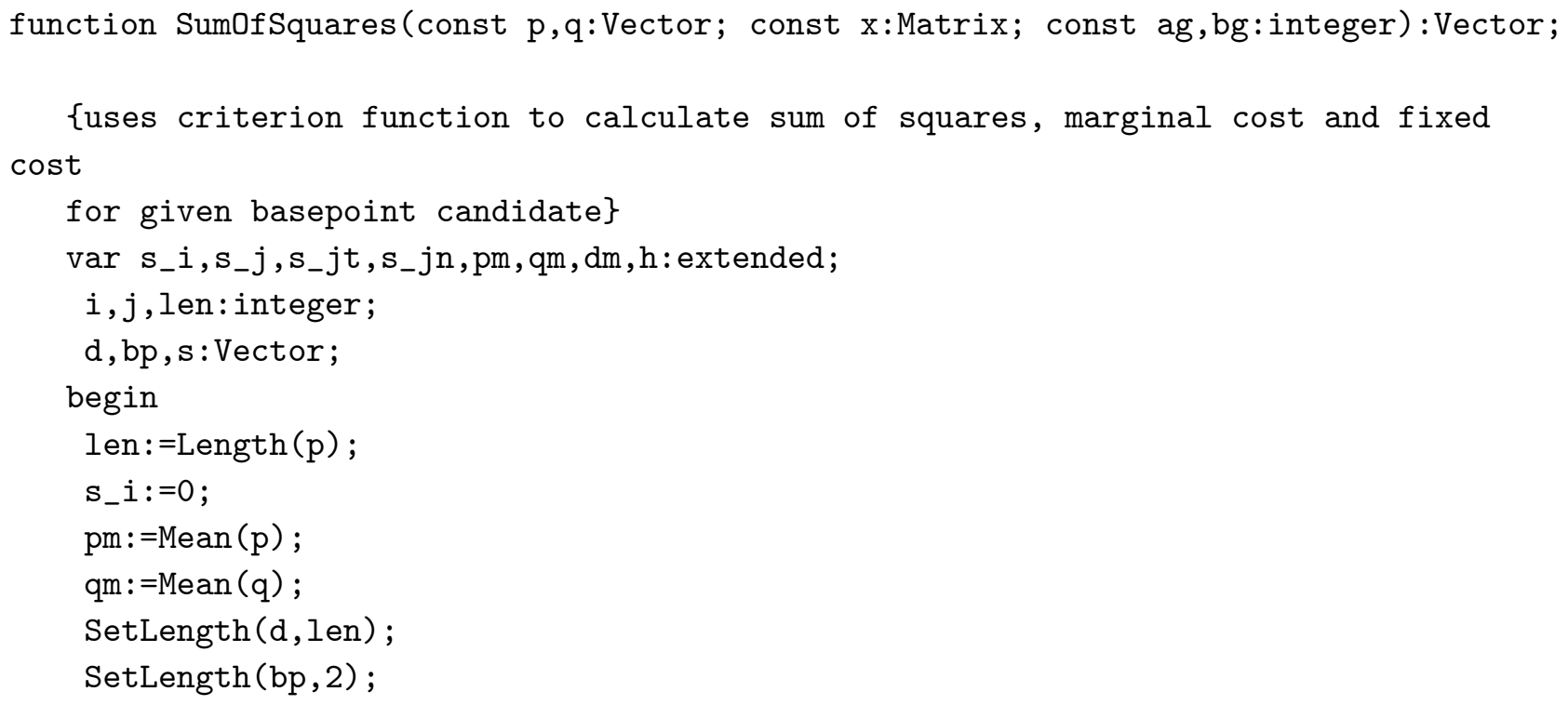


$\mathrm{bp}[0]:=\mathrm{ag} ; \operatorname{bp}[1]:=\mathrm{bg}$;

for $i:=0$ to len-1 do begin

$\mathrm{h}:=0$;

for $j:=0$ to 1 do

$\mathrm{h}:=\mathrm{h}+\operatorname{Sqr}(\mathrm{bp}[j]-\mathrm{x}[\mathrm{i}][\mathrm{j}])$;

$\mathrm{d}[\mathrm{i}]:=\operatorname{Sqrt}(\mathrm{h})$;

end;

$\mathrm{dm}:=\operatorname{Mean}(\mathrm{d})$;

$s_{-} j t:=0 ; s_{-} j n:=0$;

for $j:=0$ to len-1 do begin

$s_{-} j t:=s_{-} j t+q[j] *(p[j]-d[j])-q m *(p m-d m)$;

$s_{-} j n:=s_{-} j n+\operatorname{Sqr}(q[j])-\operatorname{Sqr}(q m)$;

end;

$s_{-} j:=s_{-} j t / s_{-} j n$;

for $i:=0$ to len-1 do begin

$s_{-} i:=s_{-} i+\operatorname{Sqr}\left(p[i]-p m+d m-d[i]+(q m-q[i]) * s_{-} j\right)$

end;

SetLength $(\mathrm{s}, 3)$;

$\mathrm{s}[0]:=\mathrm{s}_{-} i$;

$s[1]:=s_{-} j$;

$\mathrm{s}[2]:=\mathrm{pm}-(\mathrm{s}[1] * \mathrm{qm})-\mathrm{dm}$;

Sum0fSquares: $=\mathrm{s}$;

end; $\{$ SumOfSquares\}

procedure TracingBP(const base:integer; const $\mathrm{x}$ :Matrix; const $\mathrm{p}, \mathrm{q}$ :Vector; var BP:Matrix;

const $i 0, j 1, i 1, j 0:$ integer) ;

\{determines location with lowest value of sum of squares\}

var step, len_BP, intm, a, b, a0, a1 , b0, b1: integer;

sum, $c, f c$ : extended;

sos:Vector;

begin $\{$ TracingBP $\}$

step: $=50$;

len_BP : =Length (BP);

SetLength (BP, len_BP+1);

SetLength (BP [len_BP] ,4);

intm: $=\operatorname{Max}(j 1-j 0, i 1-i 0)$; 


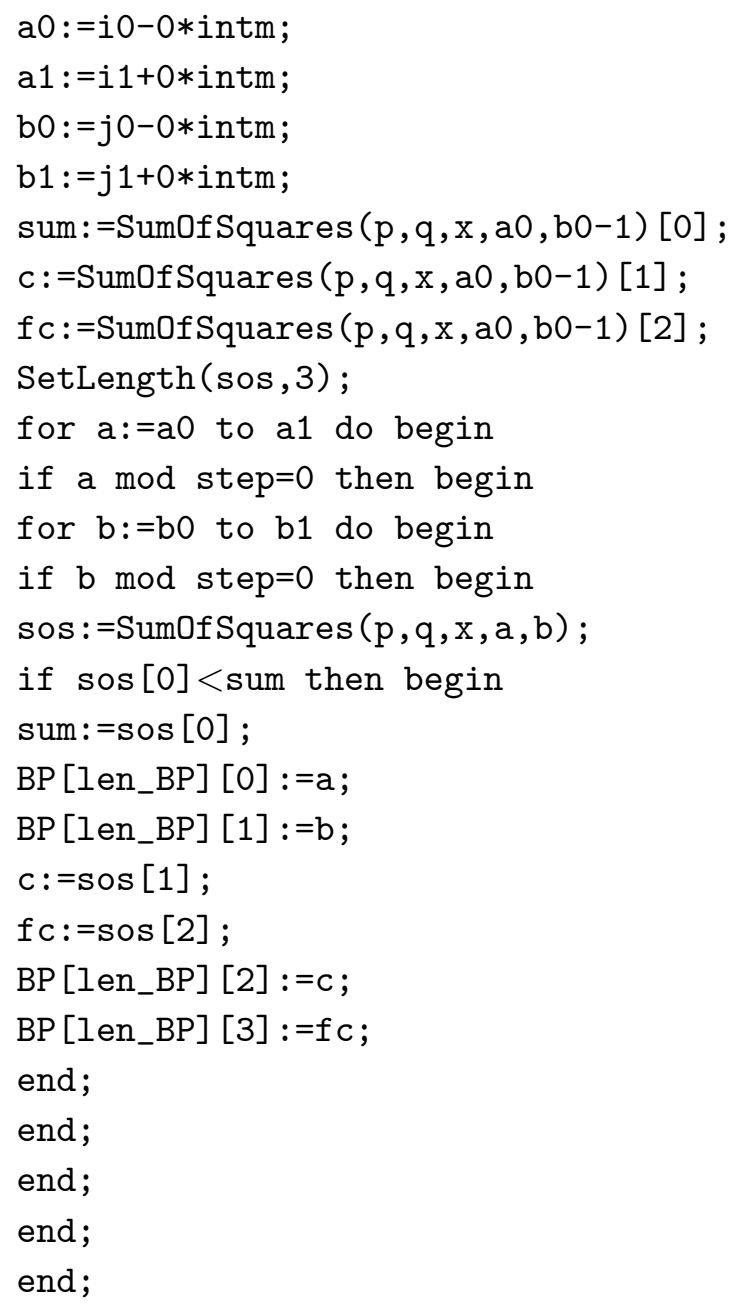




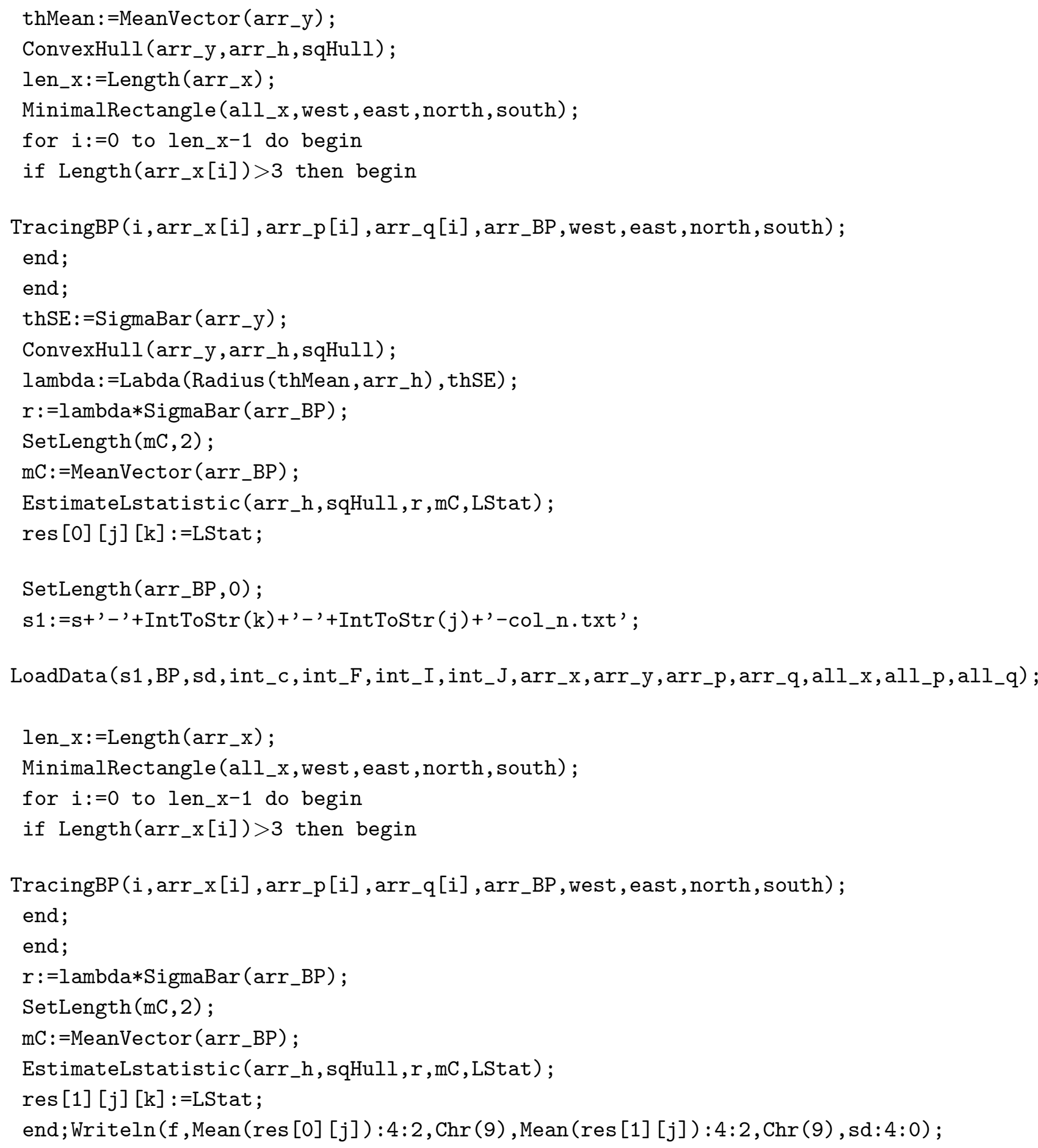


end;

Writeln('the end');

GetProfits (all_x, arr_y, BP,int_I, int_J, all_p, all_q,int_c,int_F,pi_col,pi_comp);

for $j:=0$ to int_J-1 do begin

Writeln(f, 'firm ', j+1, $\left.\operatorname{Chr}(9), p i \_c o m p[j]: 4: 2, \operatorname{Chr}(9), \operatorname{Chr}(9), \operatorname{Chr}(9), p i \_c o l[j]: 4: 2\right)$;

end;

CloseFile(f);

Readln;

end. \{main\} 